\title{
Vertical migration effects on the dispersion and recruitment of European anchovy larvae: from spawning to nursery areas
}

\author{
Andrés Ospina-Alvarez ${ }^{\mathrm{a}, *}$, Carolina Parada $^{\mathrm{b}}$, Isabel Palomera ${ }^{\mathrm{a}}$ \\ ${ }^{a}$ Institut de Ciències del Mar (CSIC), Passeig marítim de la Barceloneta 37-49, CP \\ 08003, Barcelona, Spain. \\ ${ }^{b}$ Instituto de Investigación Pesquera (INPESCA), Concepción, Chile
}

\section{Abstract}

Recruitment of European anchovy has been traditionally thought to largely depend on the passive transport and dispersion of eggs and larvae from spawning to nursery areas. Knowledge of the factors influencing the vertical distribution of fish early stages, and consequently influencing the transport, is a crucial issue in fisheries science. The aim of this study is to assess the relevance of diel vertical migration (DVM) as a mechanism involved in the transport of European anchovy larvae towards nursery areas taking into account age/stage-dependent vertical migration (i.e., the maximum migration). We developed a simplified vertical migration sub-model for anchovy larvae included in an Individual-based (IBM) hydrodynamic coupled model. Two types of simulation experiments were conducted: (1) Pure Lagrangian (passive) transport experiments and (2) biological behavior transport exper-

\footnotetext{
*Corresponding author

Email addresses: aospina.co@gmail.com (Andrés Ospina-Alvarez ), cparada@inpesca.cl (Carolina Parada), isabel@icm.csic.es (Isabel Palomera)

$U R L:$ http://andresospina.tumblr.com/ (Andrés Ospina-Alvarez )
} 
iments with a realistic scheme for egg-buoyancy, larval growth, and DVM scheme. We detected high variability in the trajectory and final position of larvae with $14 \mathrm{~mm}$ length between the passive and biological behavior experiments. The particles were less clustered in the passive transport experiment. In the biological experiment the particles were aggregated depending on the mesoscale oceanographic structures, evidencing a transport associated to filaments and meanders. The formation of schools was facilitated by the transport in filaments and larvae transported within filaments generally avoided the nucleus of the eddies and the central part of the North Current. Moreover, our results suggest that there is interconnectivity between all the anchovy sub-populations in the NW Mediterranean and that the Gulf of Lions and the the shelf waters surrounding the Ebro River Delta are the most important areas for anchovy reproduction in this region. Additionally, we detected that the pre-recruitment is higher in those years when the larvae retention is favored. We underline that bottlenecks in larval transport modelling are related to the scarcity of knowledge in developmental biology and behavior of anchovy larvae and emergent mechanistic processes.

Keywords: Anchovy, Dispersion, Recruitment, Connectivity, IBM, Vertical migration, DVM, Schooling, Mediterranean, Gulf of Lions, Ebro Delta

\section{Introduction}

The biological processes affecting the vertical position of eggs and larvae are recognized as critical components of realistic models of fish egg-larval dispersion (Brochier et al., 2008; Huret et al., 2010; Parada et al., 2003, 2008; 
Ospina-Alvarez et al., 2012). The diel vertical migration (DVM) pattern is a daily behavior that has been described for various aquatic organisms from diverse phyla. The usual pattern involves displacement from shallow depths at night to greater depths during the day (Enright and Hamner, 1967; Fortier and Leggett, 1983; Haldorson et al., 1993; Stenevik et al., 2007). Migrants appear to use deep waters as a dark daytime refuge where their probability of being predated is lower than near the surface (Gauthier and Rose, 2002; Hays, 2003) and feed near the surface, with higher available food, at night (Haney, 1988; Hays, 2003). Particularly in marine environments, there has been relatively little consideration of the causes and consequences of the individual differences in migration behavior, such as those related with the nutritional condition (Hays, 2003) and there is generally poor information available on the vertical distribution of yolk-sac and feeding larvae. However, larvae migrate towards a given maximum depth at day that depends on the larval size (i.e., larger larvae migrate deeper than smaller larvae). Previous studies were based on a migration scheme that established a fixed position for the larvae in the surface at night and at a given depth during the day (Brochier et al., 2008; Nicolle et al., 2009; Parada et al., 2008, 2012). This scheme does not take into account any of the intermediate depths during migration and that the smaller larvae have a reduced migration capacity.

Californian anchovy (Engraulis mordax) larvae have been detected at 105 $\mathrm{m}$ depth; however, $87 \%$ of the larvae occurred above $41 \mathrm{~m}$, within the upper mixed layer, which emphasizes the important role of the thermocline on the vertical positions (Ahlstrom, 1959). The vertical distribution of European anchovy (Engraulis encrasicolus) larvae was first studied by Palomera (1991). 
This study found that larvae avoid surface layers during daytime, with the larger larvae $(<10 \mathrm{~mm})$ carrying out photoperiod-related diel migrations, and thus remain in deeper waters during the day, as suggested by a high resolution sampling design (Olivar et al., 2001).

Recruitment of European anchovy has been traditionally thought to be largely dependent on the passive transport and dispersion of eggs and larvae from spawning to nursery areas (Borja et al., 1998; Hinckley et al., 1996; Mullon et al., 2002). Egg and larval transport is defined as the horizontal translocation of a particle in a bidimensional plane from an initial $\left(x_{1}, y_{1}\right)$ to a final $\left(x_{2}, y_{2}\right)$ position, that is, perpendicular and parallel to the coastline. The vertical axis (z or depth) has been ignored in order to simplify the analyses (Pineda et al., 2007). However, this dimension is critical for the transport of a biological particle (e.g., egg/early stage larvae) because the early stages of pelagic fish in the water column determine (i) the extent and direction in which they might be displaced or transported, (ii) their development rates and (iii) mortality, depending on the overlap with their predators, ambient food and physiochemical conditions; and these three factors condition impacts on (iv) pre-recruitment and recruitment success (e.g., Mullon et al., 2003; Page et al., 1989; Parada et al., 2003; Stenevik et al., 2007). Therefore, eggs and larvae might encounter different currents at various depths during their development that as a whole affect the horizontal transport. In consequence, traveling from an initial to a final position eggs and larvae are transported horizontally, but when mechanisms influencing the vertical position are considered, they may also be transported by diffusive and advective processes (Allain et al., 2001; Cowen, 2006; Epifanio and Garvine, 
2001; Haug et al., 1986; Lett et al., 2007).

Spawning patterns are a fundamental issue for understanding fish-stock variability in the context of life-history strategies (Aoki and Murayama, 1993). The environmental conditions that prevail during spawning could have an important influence on the survival of eggs and larvae. In this context, populations of small pelagic fish exhibit reproductive strategies resulting from past natural selection pressure, allowing them to adapt to high habitat variability (Brochier et al., 2009). For example: at a long timescale, anchovy and sardine regime series in Pacific populations are related to global decadal climate variability of surface air temperature (Chavez et al., 2003) probably because the species distribution contracts to a central (optimal) range during population crashes (Lecomte et al., 2004); at a short timescale, anchovy presents a seasonal trend regarding the average larval size at first feeding, this is an adaptive advantage in the winter months when cold water temperatures produce slower growth rates compared with the summer when the growth is more rapid (Hunter, 1977); at a reproductive-level behavior, European anchovy spawns preferably around midnight (Somarakis et al., 2004) to minimize the risk of being predated and maximize the eggs survival.

Moreover, variability in biometric and physiological characteristics between populations and subpopulations have been recognized as ecological advantages (Grant et al., 2010; Riveiro et al., 2011; Whitehead et al., 1988).

Knowledge of the factors influencing the vertical distribution of fish early stages, and consequently influencing the transport, is a crucial issue in fisheries science (Galarza et al., 2009; Goarant et al., 2007; Pineda et al., 2007). Many of the developed analyses are sensitive to the initial conditions of eggs 
and early-larvae in the water column: the egg production methods, models of the egg and larval survival, transport and drift and the recently developed coupled hydrodynamic-IBMs (Goarant et al., 2007; Parada et al., 2008; Ospina-Alvarez et al., 2012; Solemdal and Sundby, 1981; Stenevik et al., 2007). Studying the reproductive strategies at adequate temporal and spatial scales is crucial for understanding adult-early stages relationships.

The commercial exploitation of small pelagic fishes in the North Western Mediterranean (NWM) has been significant since the early 1940s, but it was not until the 1960s with the improvements in fishing technology that the catches of European anchovy substantially increased (Palomera et al., 2007).

The NWM Sea is formed by the northern part of the Provencal basin, the Gulf of Lions, the Ligurian Sea, the Catalan Sea and by the Balearic Sea (Millot, 1990). It covers an area of around 200,000 $\mathrm{Km}^{2}$ and presents several submarine canyons, some of which almost reaching the coast line (Millot, 1990; Salat, 1996). It is one of the most productive regions in the Mediterranean Sea, given the relatively stable coastal circulation and the discharge of two large rivers (the Rhone, in the north, and the Ebre, in the south). The discharge of the Rhone and the Ebre rivers, the wastewater from large cities, a vertical mixing, the influence of the winds and a local upwelling, are the main inputs of nutrients in the region (Millot, 1990; Salat, 1996). The discharge of these rivers brings a big input of productive water into the Mediterranean Sea, given the contributions that the rivers themselves receive from extensive agriculture and farming in their riverbed (Cruzado et al., 2002; Millot, 1990; Lloret et al., 2004). In addition to the local and regional effects of river outflows, the effect of the currents and therefore the interactions 
between the Mediterranean Sea and the Atlantic Ocean, influence the whole functioning and comportment of the NWM ecosystems. A south westward current, commonly called the Northern Current $(\mathrm{NC})$, dominates the region flowing along the edge of the continental shelf, associated with a shelf-slope front that separates the less saline inshore waters from the waters of the open sea. This creates a mesoscale-dominated system with relatively high activity and spatial and temporal variability, especially in the upper layer during the stratified season (Echevin et al., 2003; Millot, 1990).

The aim of this study is to assess how the relevance of DVM as a mechanism involved in the transport of larvae toward nursery areas taking into account age/stage-dependent vertical migration (i.e., the maximum migration). To accomplish our objectives we developed a simplified vertical migration model for European anchovy larvae in the NW Mediterranean. The DVM is included as a module in an Individual-based model (IBM) hydrodynamic coupled model. We discuss our results in the context of oceanographic processes affecting the transport and dispersion of early larvae from the spawning to the pre-recruitment zones.

\section{Methods}

In this study, we focused on the European anchovy larvae DVM effects on transport efficiency during the reproduction peak in 2007 and 2008 in the NW Mediterranean. We developed a DVM scheme that depends on age and larval stage. Processes such as spawning, egg development, hatching, larval growth and DVM were programmed into a modified version of the modelling tool ICHTHYOP (Lett et al., 2008) (Fig. 6.1). 


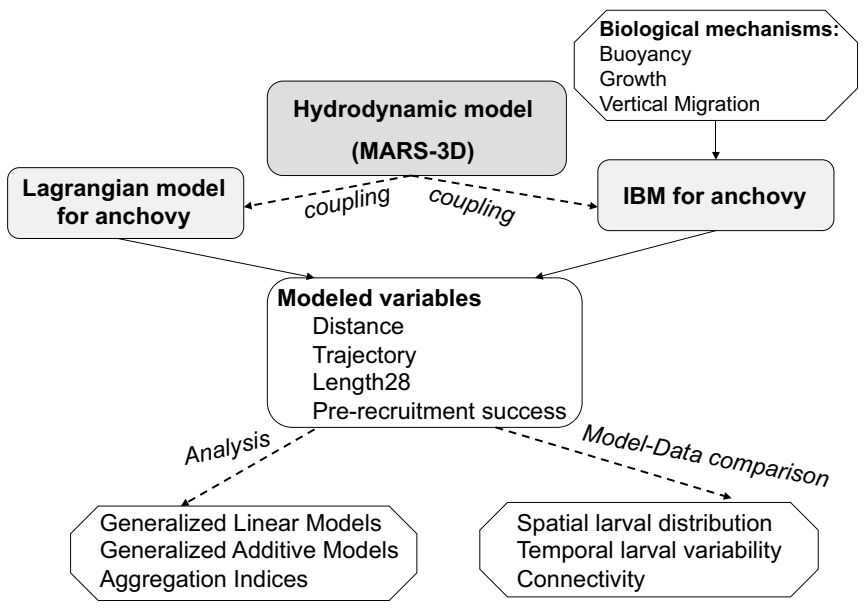

Figure 1: Conceptual diagram of the Individual-based model for European anchovy in NW Mediterranean coupled to a hydrodynamic model

\subsection{Biological data collection}

We integrated biological data from three different surveys: (1) for the larval growth sub-model we used information from data collected in the ARO2000 cruise, conducted from 31 May to 12 June 2000 (Sabatés et al., 2007) and MPOCAT cruises, conducted from May to June of 2007 and 2008; (2) for the DVM sub-model we analyzed the information from data collected in CAIMAN cruise, conducted from 31 May to 2 June 1996 (Olivar et al., 2001) and (3) to determine the total egg developmental time, the initial larvae length at hatching time, the spawning areas, the date of the high egg biomass and the released number of early-eggs, we used data collected in MPOCAT cruises (Fig. 6.2). The following sections describe the surveys, field data collection, and sub-models implemented in the IBM for European anchovy larvae. 

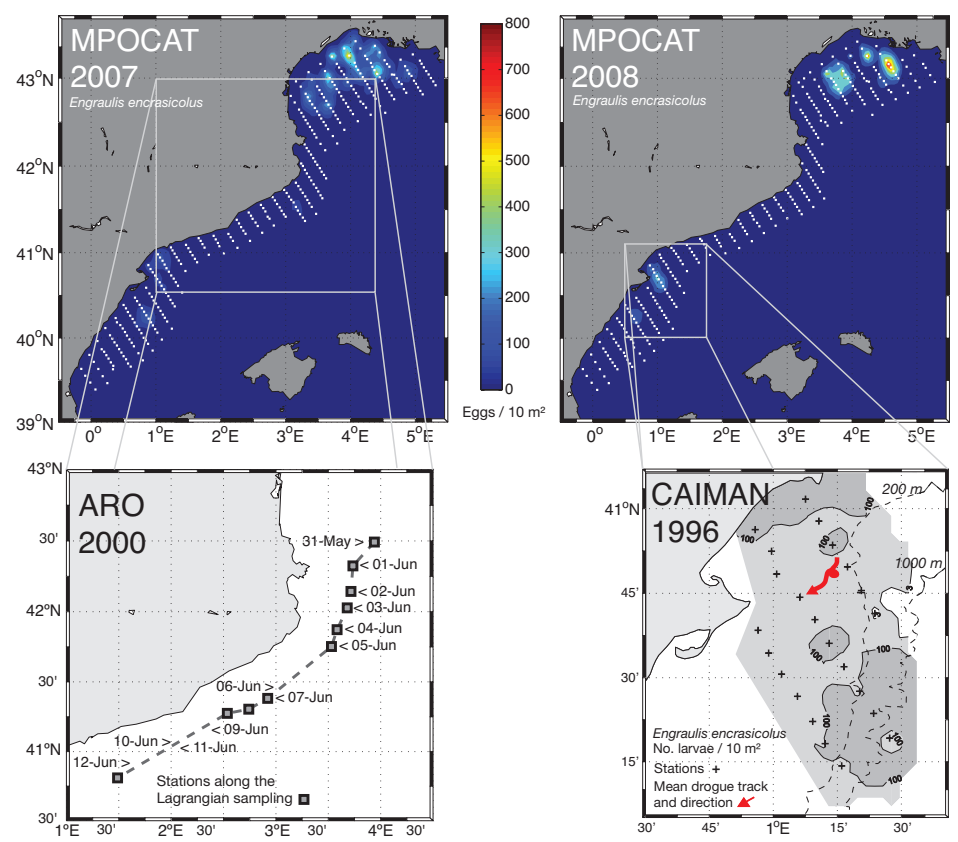

Figure 2: Above: Composite maps of European anchovy eggs in all stages collected using a CalVET net during DEPM surveys in 2007 (on the left) and 2008 (on the right), respectively. The color-scale shows the relative abundance in eggs $/ 10 \mathrm{~m}^{2}$. Stations where anchovy eggs were surveyed are indicated with white dots. Below, left: location of stations for the larval growth modelling sampling (squares). The line indicates the mean trajectory of the drifters along the Lagrangian sampling, from 31 May to 12 June 2000. Adapted from Sabatés et al. (2007); below, right: horizontal distribution of larvae during the June 1996 survey for the DVM modelling sampling. Stations where anchovy larvae were surveyed are indicated with white crosses and red arrow inside the contour map shows the mean drogue track and direction. Adapted from Olivar et al. (2001) 


\subsection{Larval growth sub-model}

To develop a larvae growth sub-model, we formulated a linear equation to calculate the length of European anchovy larvae, in millimeters, from hatching:

$$
\mathbf{L}_{(t)}=L_{(i n i)}+\omega \times t
$$

where, $L_{(t)}$ is the length of anchovy larva at time t, $L_{(i n i)}$ is the initial larval length at hatching time defined by means of egg development and hatching experiments (Ospina-Alvarez et al., 2012) from MPOCAT surveys and $\omega$ is the growth rate of anchovy larvae from samples collected in ARO2000 survey over ten days at a Lagrangian tracking experiment in the Catalan sea, NW Mediterranean.

For an individual approach, the influence of changes through the development must be included. Therefore, we developed a temperature-dependent growth model:

$$
\mathbf{L}_{(t+d t)}=L_{(t)}+(\theta \times T \times d t)
$$

where, $L_{(t+d t)}$ is the accumulative length of anchovy larva at time $t+d t$, $\theta$ is a temperature-dependent growth coefficient, $\mathrm{T}$ is the sea temperature in degrees and dt is the difference between the current step time and previous step time in days.

The daily growth rate of European anchovy larvae, $\omega$, was set at 0.57 mm day ${ }^{-1}$ for a temperature range between 18.5 and $19.0^{\circ} \mathrm{C}$ (Sabatés et al., 2007). The initial larval length at hatching time, $L_{(i n i)}$, was set at 2.79 $\mathrm{mm}$, consistent with mean length of newly hatched anchovy larvae found in 
other studies (Garcia et al., 1998; Palomera et al., 2007; Sabatés et al., 2007; Urtizberea et al., 2008) and the temperature-dependent growth coefficient, $\theta$, was set at $3.084 \times 10^{-2} \mathrm{~mm}$ day ${ }^{\circ} \mathrm{C}$ :

$$
\mathbf{L}_{(t+d t)}=L_{(t)}+\left(3.084 \times 10^{-2} \operatorname{mmday}^{\circ} \mathrm{C} \times T \times d t\right)
$$

$\theta$ was estimated in order to find the best compromise between the simulated growth rates and estimates from Palomera et al. (1988) and Sabatés et al. (2007).

\subsection{Vertical sampling and DVM sub-model}

The vertical distribution of European anchovy larvae was estimated from samples obtained at 10 stations over the continental shelf off the Ebro River Delta (NW Mediterranean), during the peak of spawning period in the summer of 1996 (Table 6.1). Further details of the field data collection can be found in Olivar et al. (2001).

\begin{tabular}{|c|c|c|c|c|c|c|}
\hline $\begin{array}{l}\text { Haul no. } \\
\text { No. }\end{array}$ & Date & $\begin{array}{c}\text { Time } \\
(\text { GMT })\end{array}$ & $\begin{array}{l}\text { Maximum } \\
\operatorname{depth}(\mathrm{m})\end{array}$ & $\begin{array}{l}\text { Latitude } \\
\text { (N) }\end{array}$ & $\begin{array}{c}\text { Longitude } \\
\text { (W) }\end{array}$ & Larvae $/ \mathbf{m}^{2}$ \\
\hline 1 & 06/07/1996 & $02: 39$ & 70 & 40.4840 & 1.1500 & 11.45 \\
\hline 2 & 06/07/1996 & 07:01 & 85 & 40.4824 & 1.1535 & 5.05 \\
\hline 3 & 06/07/1996 & $12: 09$ & 85 & 40.4734 & 1.1514 & 0.39 \\
\hline 4 & 06/07/1996 & $16: 07$ & 95 & 40.4990 & 1.1720 & 5.43 \\
\hline 5 & 06/08/1996 & $01: 13$ & 75 & 40.4766 & 1.1397 & 3.09 \\
\hline 6 & 06/08/1996 & $05: 33$ & 80 & 40.4780 & 1.1520 & 3.34 \\
\hline 7 & 06/08/1996 & $10: 48$ & 80 & 40.4991 & 1.1712 & 2.07 \\
\hline 8 & 06/08/1996 & $14: 40$ & 85 & 40.5090 & 1.1670 & 1.26 \\
\hline 9 & 06/08/1996 & $18: 25$ & 80 & 40.5123 & 1.1393 & 1.59 \\
\hline 10 & 06/08/1996 & $22: 24$ & 60 & 40.4837 & 1.1602 & 2.48 \\
\hline
\end{tabular}

Table 1: LPHR haul information for the DVM modelling sampling during the June 1996 CAIMAN survey 
Investigations have concluded that anchovy larvae appears to have a more distinct swimming behavior as size increases (Hunter, 1977; Matsuura and Kitahara, 1995), suggesting that they carry out a vertical migrational behavior characterized by a maximum (MaxDepth) and a minimum depth (MinDepth) range reached during day and night, respectively.

To develop DVM sub-model, data from CAIMAN cruise was analyzed grouping the probabilities of found anchovy larvae of an determined age or stage in the water column. We developed a linear equation to calculate a factor, $\kappa$, which relates increasing size and vertical migration potential in the range defined by the day-depth and night-depth larval position. By integrating $\kappa$ in the larval growth sub-model we obtained the larval position in the water column at any time. Eq. (4) relates factor $\kappa$ and size L.

$$
\kappa_{(L)}=0.04583 \times L+0.26666
$$

where $\kappa$ relates increasing size and vertical migration potential in the range defined by average MaxDepth and MinDepth and L is the length of anchovy larva in $\mathrm{mm}$.

The DVM sub-model was tested by predicting the depth of larvae and then validating the predictions with the field data on the vertical distribution of anchovy larvae. A non-parametric test was computed to assess the robustness of the predictions.

\subsection{IBM-hydrodynamic coupled model transport simulations}

An IBM was applied to study how physical (e.g., ocean currents, temperature, salinity) and biological (e.g., buoyancy, growth, vertical migrations) factors affect the dynamics of ichthyoplankton using velocity, temperature 
and salinity fields obtained from an hydrodynamic model. It also allowed us to track virtual drifters and the ocean properties (temperature, salinity, density) encountered by virtual particles.

\subsubsection{The DVM effects on the horizontal transport: based on an averaged climatology}

We designed a first set of experiments to test the possible DVM effects on the horizontal transport of simulated larvae using the average climatology of June-July for 2007 and 2008 from MARS-3D hydrodynamic model (Lazure and Dumas, 2008). We used an averaged climatology to avoid the influence of the daily differences on the advection and diffusion of the particles. The average climatology was calculated from MARS-3D hydrodynamic files using NetCDF Operator (NCO) Tools (Zender, 2008; Zender et al., 2011).

For each year, two types of simulation experiments were conducted: (1) Pure Lagrangian experiments (hereafter, passive transport experiments) and (2) Lagrangian with a realistic scheme for egg-buoyancy (Ospina-Alvarez et al., 2012), larval growth, and DVM scheme (hereafter, biological behavior experiments). The spawning areas were defined as the areas in the Gulf of Lions (GoL) and Catalan coast with a bathymetry between 0 and $200 \mathrm{~m}$; the spawning date was established at the 11th of June at midnight (an average spawning date from 2007 and 2008 surveys). 10,000 particles (anchovy eggs) per run were randomly released in the spawning areas from 5 to $15 \mathrm{~m}$ of depth (the depth range with more than $90 \%$ of eggs). In the passive and biological behavior experiments, larval length increased with time, at a growth rate that depends on temperature. The egg-buoyancy, larval growth and DVM sub-models were coupled in ICHTHYOP V.3 IBM (Lett et al., 2008). 
We did not use any pre-recruitment criteria, we only stopped the movement of particles at day 28, the age at which larvae can swim fast enough to influence their horizontal motion within the current field.

Thus, four simulation runs in total were performed: two passive transport experiments and two biological behavior experiments for years 2007 and 2008 .

Egg and larval transport is defined as the horizontal translocation of a particle in a bidimensional plane from an initial $\left(x_{1}, y_{1}\right)$ to a final $\left(x_{2}, y_{2}\right)$ position (Pineda et al., 2007). In contrast, egg and larval dispersal refers to the spread of eggs and larvae from a spawning source to a pre-recruitment site (Pineda et al., 2007). This definition is consistent with the natal dispersal concept from terrestrial ecology (Clobert et al., 2001; Begon et al., 2006).

We selected orthodromic distance (i.e., the shortest distance between any two points on the surface of a sphere) and the drift trajectory (i.e., the accumulative distance of all segments traveled) as an indicator of the differences in the horizontal transport between the experiments. The orthodromic distance (hereafter referred to as distance) indicates dispersion and drift trajectory (hereafter referred to as trajectory) indicates transport (Pineda et al., 2007).

Distances and trajectories were measured based on code developed in MATLAB v7.12 (The MathWorks Inc., 2011). The distances and trajectories traveled by the particles affect larval growth. This can be quantified by the larval length at 28 days after spawning (hereafter length28). As the data were not normally distributed, nonparametric statistical analysis were performed. The distances, trajectories and lengths28 of particles from the passive transport and biological behavior experiments for each year were 
compared using the Mann-Whitney-Wilcoxon test (MWW), unpaired and two-sides, based on code developed in R v.2.13.1 (R Development Core Team, 2010).

The null hypothesis of no relationship between the spatial distribution of particles at 28 days after spawning in passive transport and biological behavior experiments was evaluated by the Mantel test (Mantel, 1967). Geographic distance was used as the dissimilarity measurement and the critical p-value was estimated by randomization (Monte Carlo) test with 999 permutations using the package "ape" in R v.2.13.1 (R Development Core Team, 2010).

Local (nearest neighbor) spatial pattern analysis, in the form of the aggregation index (R, Clark and Evans, 1954) modified to account for edge effects, was used to characterize the horizontal larval distribution pattern. The nearest neighbor distance distribution function $\mathrm{G}(\mathrm{r})$ of the stationary point process was estimated from a point pattern in a window of arbitrary shape using the Kaplan-Meier type edge correction. Then the mean of the distribution was calculated from the Cumulative Distribution Function method (a detailed explanation in "spatstat" package help in R v.2.13.1; R Development Core Team, 2010). The aggregation index relates the observed average distance of all larvae to their respective nearest neighbors with the average distance expected under a random or Poisson spatial distribution. The aggregation index ranges from 0 (maximum clustering) to 2.15 (regular hexagonal pattern). Values below 1.0 indicate a clustered pattern, values around 1.0 shows a random pattern, and values above 1.0 indicates a regular pattern. 


\subsubsection{The DVM influence on the horizontal transport}

To set a realistic dynamic scenario, the complete available fields of MARS3D hydrodynamic model and realistic egg-density and spawning dates derived from MPOCAT 07/08 surveys were used. This allowed us to study the possible inter-annual effects of the DVM behavior on the individual prerecruitment and transport successes. That set of experiments include the most realistic scenarios possibly made up to date with the available biological data.

We established the spawning areas and the date of high egg biomass in 2007 and 2008 using the information from egg density samples collected during the MPOCAT surveys in May-June 2007/08. The area covered encompassed the totality of the European anchovy main spawning grounds in Northwestern Mediterranean (Catalan Sea and GoL). Eggs and early larval stages were located in the surface layers of the water column, above the thermocline, with $90 \%$ of eggs found in the upper $15 \mathrm{~m}$, according with previous studies Olivar et al. (2001) and Palomera (1991). Therefore, eggs were collected at vertical hauls using a California Vertical Egg Tow (CalVET) net of $0.25 \mathrm{~m}$ mouth diameter with a $150 \mu \mathrm{m}$ of mesh size at a maximum depth of $100 \mathrm{~m}$. The volume of water filtered by the net was recorded with a flowmeter attached to the mouth of the net. The eggs were classified in development stages according Moser and Ahlstrom (1985) and converted in age (hours from the spawning) following Lo (1985). Egg abundances were standardized to number per squared meters.

To establish the appropriate number of particles in the transport experiments, we perform repeated trials increasing the amount of particles at 
release $(1000 ; 5000 ; 10,000 ; 15,000 ; 20,000$ and 50,000), forming the ensemble average and standard deviation, and determining when these statistics stabilize (Brickman and Smith, P.C., 2002). We established that 10,000 particles represented the desired ensemble average.

We only selected data corresponding to early egg-stages from MPOCAT 07/08 surveys to establish an initial number of particles released per quadrant in each experiment. 9218 and 9220 particles for each spawning date, from 5 to $15 \mathrm{~m}$ of depth, were released in 2007 and 2008, respectively. Each released particle represents $1 \times 10^{8}$ anchovy eggs in early stages. The number per quadrant is variable and represents the field egg abundance (Fig. 6.3).

Subsequently, we conducted passive and biological behavior experiments with six spawning dates at midnight of 1, 6, 11, 16, 21 and 26 of June.

\subsubsection{The DVM effects on the growth, distance and trajectories travelled by anchovy larva}

In both, passive and biological behavior experiments, the larval length increased over time at a growth rate that depended on temperature. The pre-recruitment criteria was established at $14 \mathrm{~mm}$ of length which was the assumed size when the larvae was able to swim fast (Somarakis and Nikolioudakis, 2010). To evaluate the pre-recruitment success in a geographic context we established 7 release or pre-recruitment zones: GoL East, GoL West, Palamos, Barcelona, Ebro Delta, Gulf of Valencia (GV) and Balearic Islands (Fig. 6.3). The nursery areas for European anchovy in the NW Mediterranean could include all shallow (i.e., $<250 \mathrm{~m}$ ) and low salinity oceanic waters as a result of rivers discharges (i.e., $<37.50$ ). A total of 24 simulation runs were conducted: six, one for each spawning date, passive 

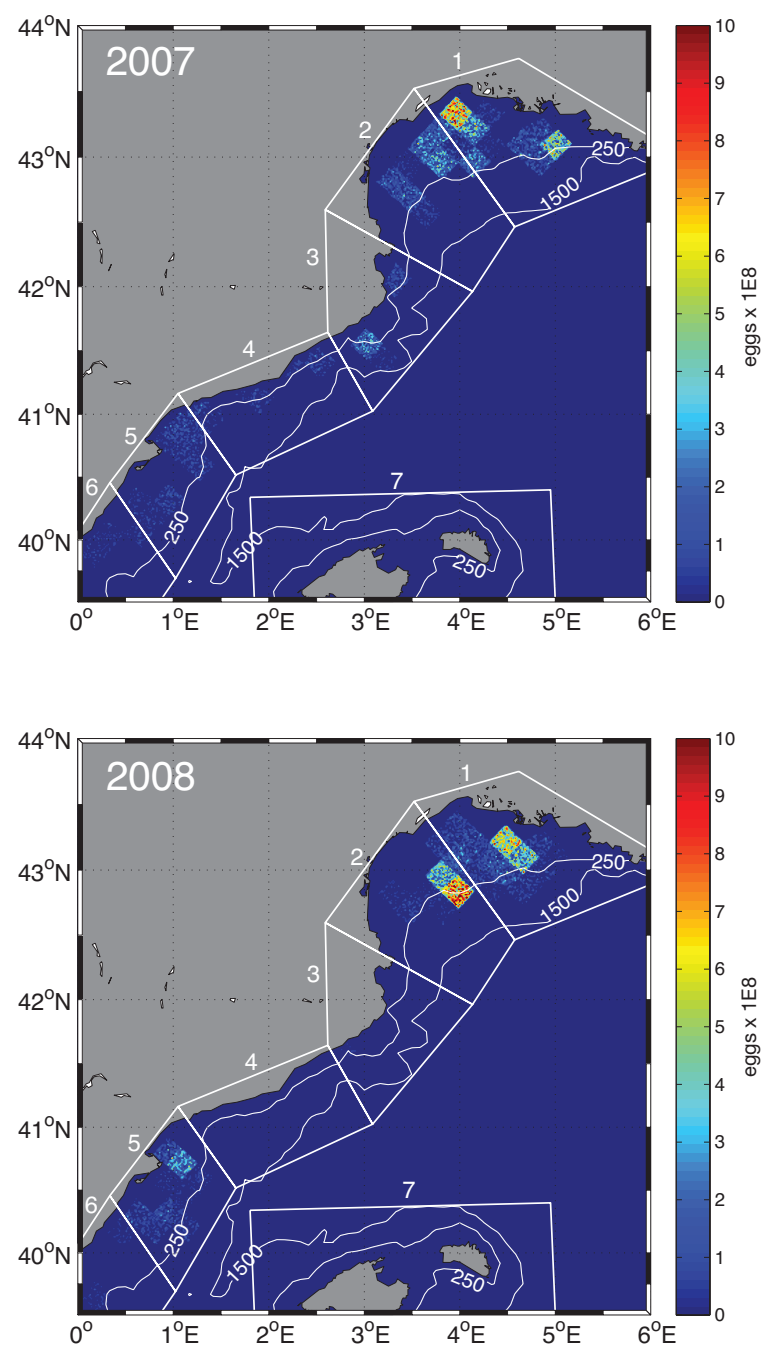

Figure 3: Release position of particles in passive and biological behavior experiments determined from annual (May-June) pelagic spawner biomass surveys over the period 2007-2008 and release/pre-recruitment zones in experiments: 1- GoL East, 2- GoL West, 3- Palamos, 4- Barcelona, 5- Ebro delta, 6- Gulf of Valencia and 7- Balearic Islands. The bathymetric contour lines for $250 \mathrm{~m}$ and $1500 \mathrm{~m}$ are showed. The color-scale represents eggs $\times 10^{8}$. 
transport experiments (as control) and six biological.

In order to assess the effect of DVM behavior on inter-annual variability on the horizontal transport pattern, we measured the distance and trajectory for each particle using codes developed in MATLAB v7.12.0 (The MathWorks Inc., 2011). Since the data was not normally distributed, nonparametric statistical analysis were performed. The distances, trajectories and lengths28 of particles from the passive transport and biological behavior experiments for each year were compared using the MWW test, unpaired and two-sides, in R v.2.13.1 (R Development Core Team, 2010). We assumed larvae retention when the distance traveled was below the threshold value $(96.77 \mathrm{~km})$. This threshold was the distance covered during 28 days at $4 \mathrm{~cm} \times \mathrm{s}^{1}$ from their release point, according with Lett et al. (2007).

\subsection{Sensitivity analysis: individual pre-recruitment and transport success}

The individual pre-recruitment success is a binary response representing the 'success' or 'failure' to reach the nursery areas for each particle released. Transport success (TS) is defined as the particles that were transported to a nursery area divided by the total number of particles released in the experiment. We divided the TS into two components: outsider transport success (OTS) and local transport success (LTS): (1) the OTS is defined by the number of particles transported to a nursery area that come from some of the other six remaining release/pre-recruitment areas divided by the total of particles released; (2) the LTS is defined by the number of particles transported to a nursery area that come from the same release/pre-recruitment area divided by the total of particles released. OTS is related to connectivity while LTS with retention process. 
The objective of sensitivity analysis was to evaluate the average behavior of the biological experiments from the IBM-hydrodynamic coupled model for the dependent variable (i.e., individual pre-recruitment success). The sensitivity analysis was performed using a multi-factor analysis of variance from the GLM module of R (R Development Core Team, 2010). The independent factors selected for the analysis were: release date, release zone, the release depth range, initial temperature range, initial salinity range and initial sea-floor depth range. Logistic regressions were used to assess whether individual pre-recruitment success significantly differed according to initial environmental factors.

Additionally, the effects of the initial conditions (i.e., longitude, latitude, sea-floor depth, release depth, temperature and salinity) on the individual pre-recruitment success were examined by Generalized Additive Models (GAMs). GAMs, which are able to deal with non-linear relationships between a dependent variable and multiple predictors in the same model, are non-parametric generalizations of multiple linear regression that are less restrictive in assumptions about the underlying distribution of data (Hastie and Tibshirani, 1990). In GAMs, a pre-defined link function is related to predictor variables by scatter-plot smoothers in lieu of least-squares fits. Since the pre-recruitment success is in a success/failure format, a binomial error distribution was used. The natural cubic spline smoother was chosen as the most appropriate for the explanatory variables. The spline bases have good theoretical and practical properties (see Hastie and Tibshirani, 1990, for a detailed discussion). The cubic smoothing spline tends to smooth over extremely high curvature regions. If interpreted the right way, the confidence 
intervals appear to be amazingly reliable and generally tend to reflect what is going on (Silverman, 1985).

\section{Results}

\subsection{Larval growth sub-model}

We simulate the growth in length of individuals as a function of water temperature. Length increases linearly with time, at a growth rate that is a linear function of temperature. Using a $\theta$ value of $3.084 \times 10^{-2} \mathrm{~mm}$ day ${ }^{\circ} \mathrm{C}$, there are significative differences between passive and biological behavior experiments for 2007 and 2008 when the length28 is compared (p-value $<0.001$,

in both cases, MWW test). The mean length28 is significantly lower in the biological than in the passive transport experiments for 2007 and 2008 $(16.43 \mathrm{~mm}<17.01 \mathrm{~mm}$ in 2007 and $16.06 \mathrm{~mm}<16.98 \mathrm{~mm}$ in 2008).

\subsection{DVM sub-model}

Traditionally, in larval transport simulations a deterministic pattern in which organisms reside at different depths at daytime and night-time is impose. By integrating Eq. (4) and larvae growth sub-model (Eq. (3)) we proposed a method to calculate the individual larval position in the water column:

$$
\gamma_{(t)}=\kappa \times\left[\left(-\sin \frac{\pi(t-3600)}{24 \times 3600}\right)^{2} \times \Delta \text { Depth }- \text { MinDepth }\right]
$$

where $\gamma_{(t)}$ is the depth of larva at time $\mathrm{t}$, $\mathrm{t}$ is daytime in seconds and $\Delta$ Depth is the difference between MaxDepth and MinDepth.

The DVM sub-model (Eq. (5)) can calculates changes in the vertical position of larvae over time, from hatch until $16 \mathrm{~mm}$ of length for each 
length class at day and night separately. However, for an improved graphic representation of the model, larvae is showed at $4 \mathrm{~mm}$ size intervals (Fig. $6.4)$.

\subsection{The DVM influence on the horizontal transport}

This section refers to the transport experiments using an average climatology from June-July for 2007 and 2008 from MARS-3D model. There are significant differences between passive and biological behavior experiments for the whole dataset when distances and trajectories are compared (p-value $=0.0014$ and $\mathrm{p}$-value $<0.001$, respectively from MWW test). The mean distance and trajectories are significantly lower in biological than passive transport experiments $(75.64 \mathrm{~km}<80.53 \mathrm{~km}$ and $171.12 \mathrm{~km}<177.28 \mathrm{~km}$, respectively).

However, considering the two years separately, we detected inter-annual variability, as in 2007 there are no significant differences between the passive and biological behavior experiments regarding distances and trajectories (pvalues $<0.05$, MWW test), while differences are highly significant in 2008 (both p-values are $<0.001$, MWW test). In 2008, the mean distance is significantly lower in the biological than in the passive transport experiments $(55.57 \mathrm{~km}<62.40 \mathrm{~km})$ and the mean trajectory travelled is significantly lower in the biological than in the passive transport experiments $(115.85 \mathrm{~km}<134.39$ $\mathrm{km})$.

By using the Mantel test to evaluate spatial differences in the position of larvae 28 days after spawning, we conclude that the location of the larvae is different between Lagrangian and biological behavior transport experiments for 2007 and 2008. Significant p-values were calculated for the two years, 
Probability of anchovy larvae $\bigcirc \quad$ Model prediction of depth larvae -
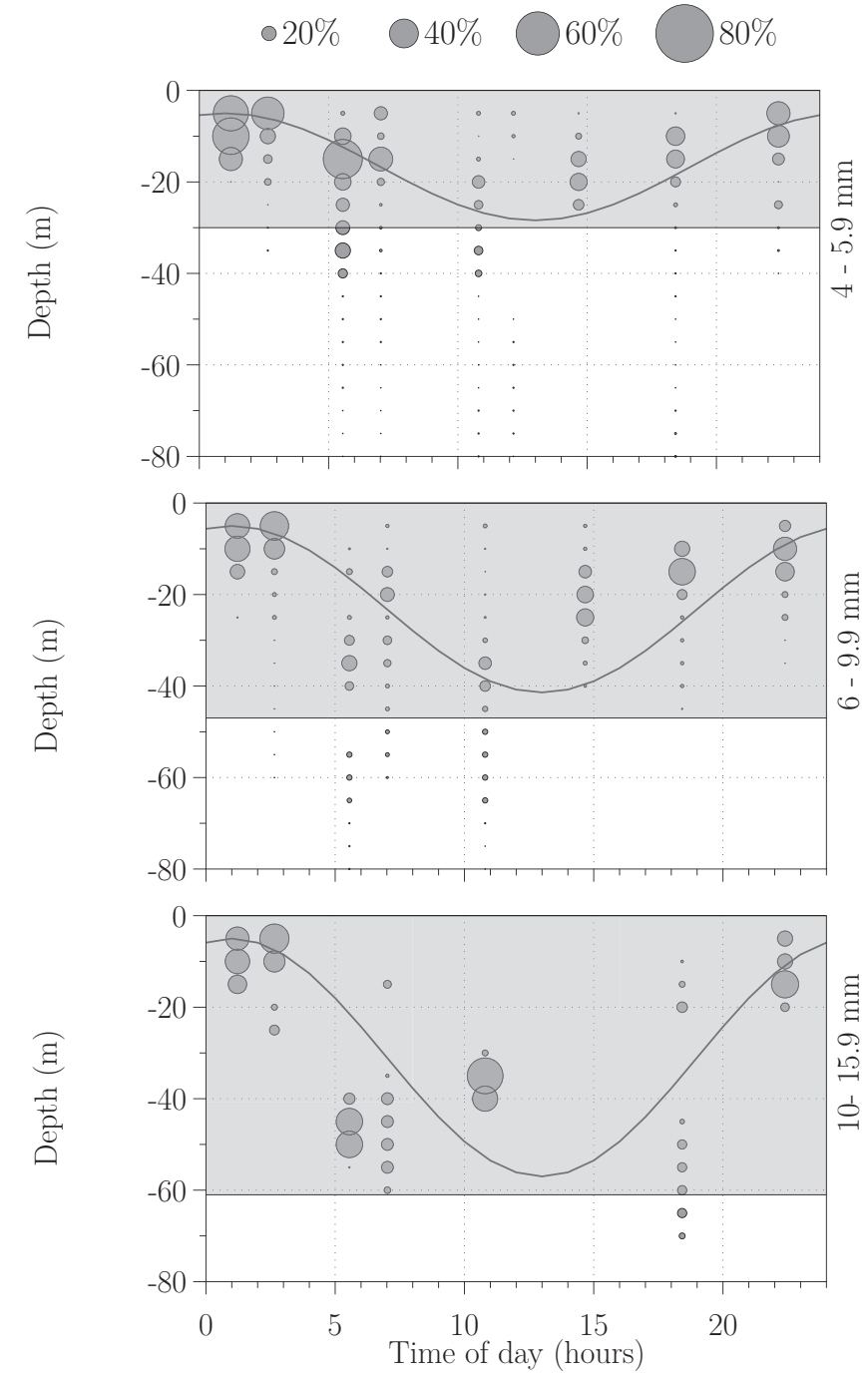

Figure 4: Vertical distribution of European anchovy larvae from field data and modeled DVM scheme of anchovy larvae used in IBM. Values are plotted by size range (4.0-5.9, 6.09.9 and 10.0-15.9 mm) in percentages of the total abundance at each sampling time (dark gray bubbles), the gray area represents the average migration extent and the continuous line represents the DVM model. 
0.53 and 0.74 , respectively.

The aggregation indices for the spatial patterns ranged between 0.36 and 0.48 and are consistent with a clustered pattern. However, the biological behavior experiments show lower indices than Lagrangian transport experiments for 2007 and 2008 (Table 6.2).

\begin{tabular}{llll}
\hline $\begin{array}{c}\text { Year/type of } \\
\text { experiment }\end{array}$ & $\begin{array}{c}\text { Lagrangian } \\
\text { transport }\end{array}$ & $\begin{array}{c}\text { Biological } \\
\text { behavior }\end{array}$ & p-Value \\
\hline $\mathbf{2 0 0 7}$ & 0.48 & 0.36 & $<2.2 \times 10^{-16}$ \\
$\mathbf{2 0 0 8}$ & 0.46 & 0.40 & $<2.2 \times 10^{-16}$ \\
\hline
\end{tabular}

Table 2: Aggregation indices for the spatial patterns resulting after 28 days of transport in Lagrangian and biological behavior experiments using an average climatology.

\subsection{The DVM effects on the growth, distance and trajectories travelled by} anchovy larva

If we use the complete available series data from June to July 2007 and 2008 from MARS-3D hydrodynamic model, the passive and biological behavior experiments show significative differences when distances, trajectories and length28 are compared (p-value $<0.001$ in all cases, MWW test). These results confirm differences detected in our previous experiments using an average climatology series. The deviance explained for the effects of the type of experiment on the particle transport is low, although statistically significant (Table 6.3).

However, there are statistically significative differences at a 0.95 probability level in the position of particles 28 days after release between Lagrangian and biological behavior transport experiments for all dates pairs in 2007 and 2008 (a graphical example of these differences in Fig 5). Moreover, the ag- 


\begin{tabular}{|c|c|c|c|c|c|c|c|}
\hline \multicolumn{8}{|c|}{$\begin{array}{l}\text { GLM: distance } \sim \text { type experime } \\
\text { Model deviance explained: } 32.97 \%\end{array}$} \\
\hline & Df & Sum Sq & Mean Sq & $\mathbf{F}$ value & $\operatorname{Pr}(>\mathbf{F})$ & Exp Var & \\
\hline Type exp. & 1 & 38363947 & 38363947 & 4488.1 & $<2.2 \times 10^{-16}$ & $1.50 \%$ & $* * *$ \\
\hline Rele. date & 11 & 761147964 & 69195269 & 8094.9 & $<2.2 \times 10^{-16}$ & $29.67 \%$ & $* * *$ \\
\hline Rele. zone & 5 & 6992346 & 1398469 & 163.6 & $<2.2 \times 10^{-16}$ & $0.27 \%$ & $* * *$ \\
\hline Residuals & 205807 & 1759241569 & 8548 & & & $68.57 \%$ & \\
\hline
\end{tabular}

GLM: trajectory $\sim$ type experiment + release date + release zone, family $=$ gaussian() Model deviance explained: $62.89 \%$

\begin{tabular}{|c|c|c|c|c|c|c|c|}
\hline & Df & Sum Sq & Mean Sq & F value & $\operatorname{Pr}(>\mathbf{F})$ & Exp Var & \\
\hline Type exp. & 1 & 4846889 & 4846889 & 439.29 & $<2.2 \times 10^{-16}$ & $0.08 \%$ & $* * *$ \\
\hline Rele. date & 11 & 3640654135 & 330968558 & 29996.53 & $<2.2 \times 10^{-16}$ & $60.15 \%$ & $* * *$ \\
\hline Rele. zone & 5 & 136427945 & 27285589 & 2472.96 & $<2.2 \times 10^{-16}$ & $2.25 \%$ & $* * *$ \\
\hline Residuals & 205807 & 2270783883 & 11034 & & & $37.52 \%$ & \\
\hline \multirow{2}{*}{\multicolumn{8}{|c|}{ GLM: length28 $\sim$ type experiment + release date + release zone, family $=$ gaussian ()}} \\
\hline & & & & & & & \\
\hline & Df & Sum Sq & Mean Sq & F value & $\operatorname{Pr}(>\mathbf{F})$ & Exp Var & \\
\hline Type exp. & 1 & 50931 & 50931 & 74141 & $<2.2 \times 10^{-16}$ & $14.61 \%$ & $* * *$ \\
\hline Rele. date & 11 & 103326 & 9393 & 13674 & $<2.2 \times 10^{-16}$ & $29.64 \%$ & $* * *$ \\
\hline Rele. zone & 5 & 52962 & 10592 & 15419 & $<2.2 \times 10^{-16}$ & $15.19 \%$ & $* * *$ \\
\hline Residuals & 205807 & 141379 & 1 & & & $40.56 \%$ & \\
\hline
\end{tabular}

Signif. code: $* * * \mathrm{p}<0.001$

Type of experiment: passive transport or biological behavior experiment;

Release date: $1^{\text {st }}, 6^{\text {th }}, 11^{\text {th }}, 16^{\text {th }}, 21^{\text {st }}$ and $26^{\text {th }}$ of June 2007 or June 2008;

Release zone: 1- GoL East, 2- GoL West, 3- Palamos, 4- Barcelona, 5- Ebro delta, 6- Gulf of Valencia

Table 3: The DVM effects on the horizontal transport. Transport experiments based on the complete series from MARS-3D. The selected parsimonious GLM's, deviance variance explained and statistics from ANOVA applied to the IBM output for the dependent variables: distance, trajectory and length28. 
gregation indices for the spatial patterns in biological behavior experiments were lower than those in Lagrangian transport experiments for all dates pairs in 2007 and 2008 .

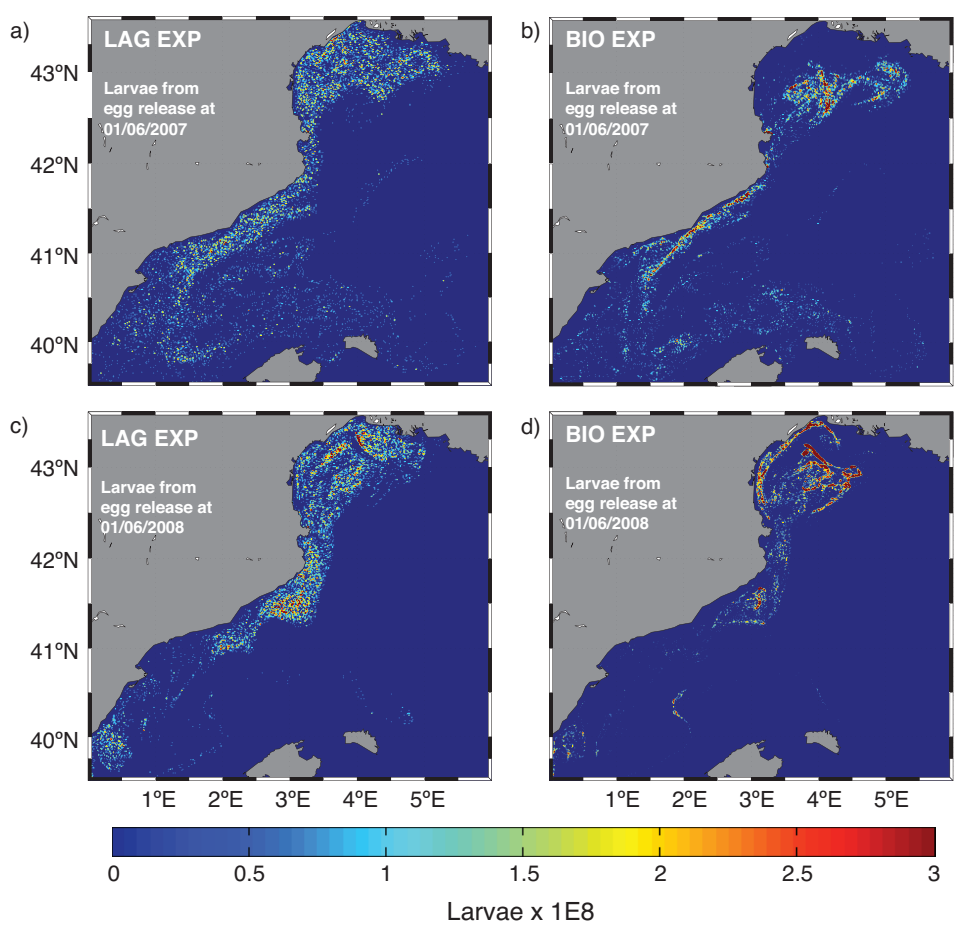

Figure 5: Simulated horizontal distributions of European anchovy larvae at $14 \mathrm{~mm}$ from the IBM in passive and biological experiments. a) and b) The output of passive and biological behavior experiments establishing the spawning date at $1^{\text {st }}$ of June 2007; (c and d) establishing the spawning date at $1^{\text {st }}$ of June 2008. The type of experiment and release date is indicated in the upper left corner of each map. The color-scale represents larvae $\times 10^{8}$.

Hereafter, we only refer to the biological experiments: transport experiments using the complete available data series from June to July for 2007 and 2008 from MARS-3D hydrodynamic model, a realistic egg-density, spawning dates from MPOCAT 07/08 surveys and the DVM scheme. 
There are significative differences between 2007 and 2008 when distances, trajectories and length28 are compared $(\mathrm{p}$-value $<0.001$ in all cases, MWW test). The mean distance, trajectory and length28 are significantly lower in 2008 than in $2007(84.33 \mathrm{~km}<224.28 \mathrm{~km}, 216.21 \mathrm{~km}<500.05 \mathrm{~km}$ and $16.27 \mathrm{~mm}<16.32 \mathrm{~mm}$, respectively).

\subsection{Sensitivity analysis: individual pre-recruitment and transport success}

The sensitivity analysis that was performed with a GLM, and used to evaluate the effects of the independent factors on the individual pre-recruitment success in the IBM-hydrodynamic coupled model, is significant (p-value < 0.001). However, it shows that the initial conditions (i.e., release date, release zone, sea-floor depth range, release depth range, temperature range and salinity range) can only explain approximately $15 \%$ of the individual prerecruitment success (Fig. 6.6). The release (spawning) date has an important effect on the pre-recruitment success, followed by the sea water salinity and the sea-floor depth at spawning time.

The sensitivity analysis selecting the best GAM possible and used to evaluate the effects of the independent variables on the individual pre-recruitment success in the IBM-hydrodynamic coupled model is significant and shows that the initial conditions (i.e. release date, latitude, longitude, depth of release, sea-floor depth, sea water temperature and sea water salinity at spawning time) can only explain approximately $18 \%$ of the individual pre-recruitment success. In both cases, GLM's and GAM's are not able to predict the prerecruitment when only taking into account the initial conditions (Fig. 6.6, Table 6.4).

There are significative differences between 2007 and 2008 when the po- 


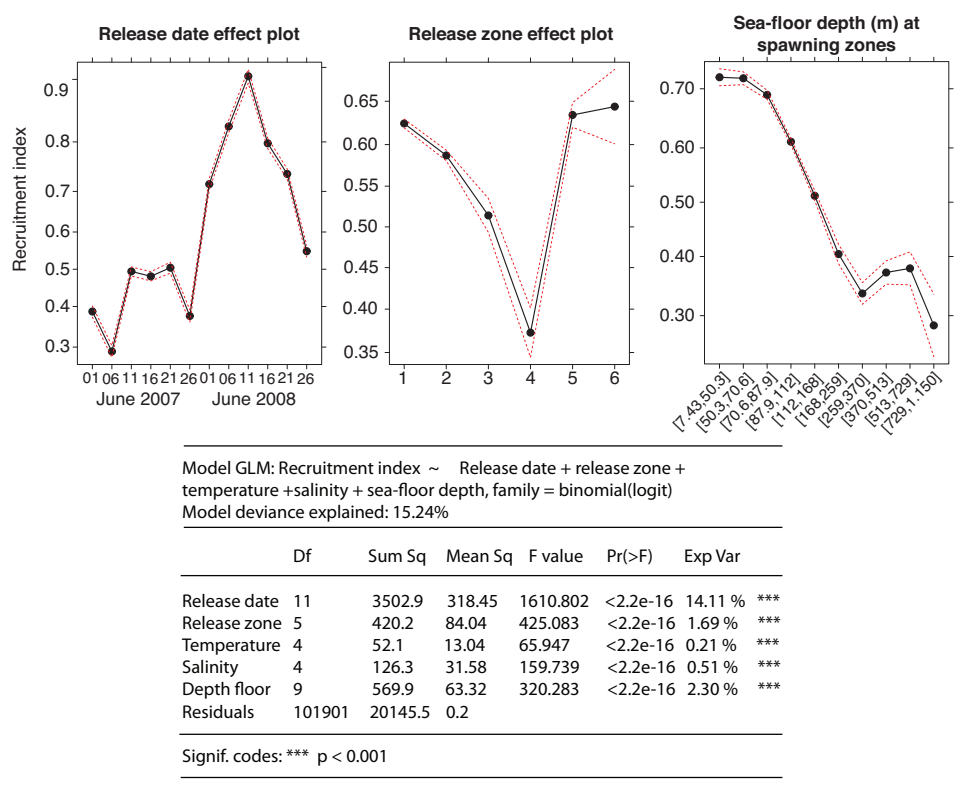

Figure 6: Initial conditions effects of the factors that explain more than $1 \%$ of variance of the pre-recruitment success. Statistics of the parsimonious GLM applied to the IBM output for the dependent variable pre-recruitment success are showed. 
GAM: recid $\sim$ releasedate $+\mathrm{s}($ latini, lonini $)+\mathrm{s}($ tempini, salini $)$

$+\mathrm{s}($ depthini $)+\mathrm{s}($ floorini $)$, family $=\operatorname{binomial}()$

Parametric coefficients:

\begin{tabular}{lrrrrr} 
& Estimate & Std. Error & $\mathbf{z}$ value & $\operatorname{Pr}(>|z|)$ & \\
\hline (Intercept) & -0.55159 & 0.04306 & -12.810 & $<2.2 \times 10^{-16}$ & $* * *$ \\
$\mathbf{0 6 / 0 6 / 2 0 0 7}$ & -0.55124 & 0.03430 & -16.070 & $<2.2 \times 10^{-16}$ & $* * *$ \\
$\mathbf{0 6 / 1 1 / 2 0 0 7}$ & 0.44271 & 0.04406 & 10.047 & $<2.2 \times 10^{-16}$ & $* * *$ \\
$\mathbf{0 6 / 1 6 / 2 0 0 7}$ & 0.58997 & 0.05443 & 10.839 & $<2.2 \times 10^{-16}$ & $* * *$ \\
$\mathbf{0 6 / 2 1 / 2 0 0 7}$ & 0.75206 & 0.06741 & 11.156 & $<2.2 \times 10^{-16}$ & $* * *$ \\
$\mathbf{0 6 / 2 6 / 2 0 0 7}$ & 0.35578 & 0.07324 & 4.857 & $1.19 \times 10^{-06}$ & $* * *$ \\
$\mathbf{0 6 / 0 1 / 2 0 0 8}$ & 1.00887 & 0.06028 & 16.737 & $<2.2 \times 10^{-16}$ & $* * *$ \\
$\mathbf{0 6 / 0 6 / 2 0 0 8}$ & 2.10940 & 0.06122 & 34.458 & $<2.2 \times 10^{-16}$ & $* * *$ \\
$\mathbf{0 6 / 1 1 / 2 0 0 8}$ & 2.70075 & 0.05683 & 47.520 & $<2.2 \times 10^{-16}$ & $* * *$ \\
$\mathbf{0 6 / 1 6 / 2 0 0 8}$ & 2.18318 & 0.05652 & 38.626 & $<2.2 \times 10^{-16}$ & $* * *$ \\
$\mathbf{0 6 / 2 1 / 2 0 0 8}$ & 1.74065 & 0.06426 & 27.089 & $<2.2 \times 10^{-16}$ & $* * *$ \\
$\mathbf{0 6 / 2 6 / 2 0 0 8}$ & 0.91055 & 0.07369 & 12.356 & $<2.2 \times 10^{-16}$ & $* * *$ \\
\hline
\end{tabular}

Approximate significance of smooth terms:

\begin{tabular}{lrrrrr}
\hline & edf & Ref.df & Chi.sq & p-value & \\
\hline s(latini,lonini) & 28.737 & 28.994 & 2080.260 & $<2.2 \times 10^{-16}$ & $* * *$ \\
s(tempini,salini) & 28.494 & 28.983 & 1840.049 & $<2.2 \times 10^{-16}$ & $* * *$ \\
s(depthini) & 1.545 & 1.908 & 6.738 & 0.0313 & $*$ \\
s(floorini) & 8.728 & 8.977 & 230.227 & $<2.2 \times 10^{-16}$ & $* * *$ \\
\hline
\end{tabular}

Signif. codes: ${ }^{\prime * * *}, 0.001^{\prime *}, 0.05$

R-sq. $(\mathbf{a d j})=0.223$;

Deviance explained $=18.2 \%$;

UBRE score $=0.11451$.

Table 4: Statistics of the parsimonious GAM applied to the IBM output for the dependent variable pre-recruitment success. The abbreviations correspond to: latitude, longitude, temperature, salinity spawning depth and floor depth at spawning time. 
sition of anchovy larvae at $14 \mathrm{~mm}$ length are compared (p-value $<0.001$ ) (Fig. 6.7). These differences in the general transport pattern affect the pre-recruitment and TS.
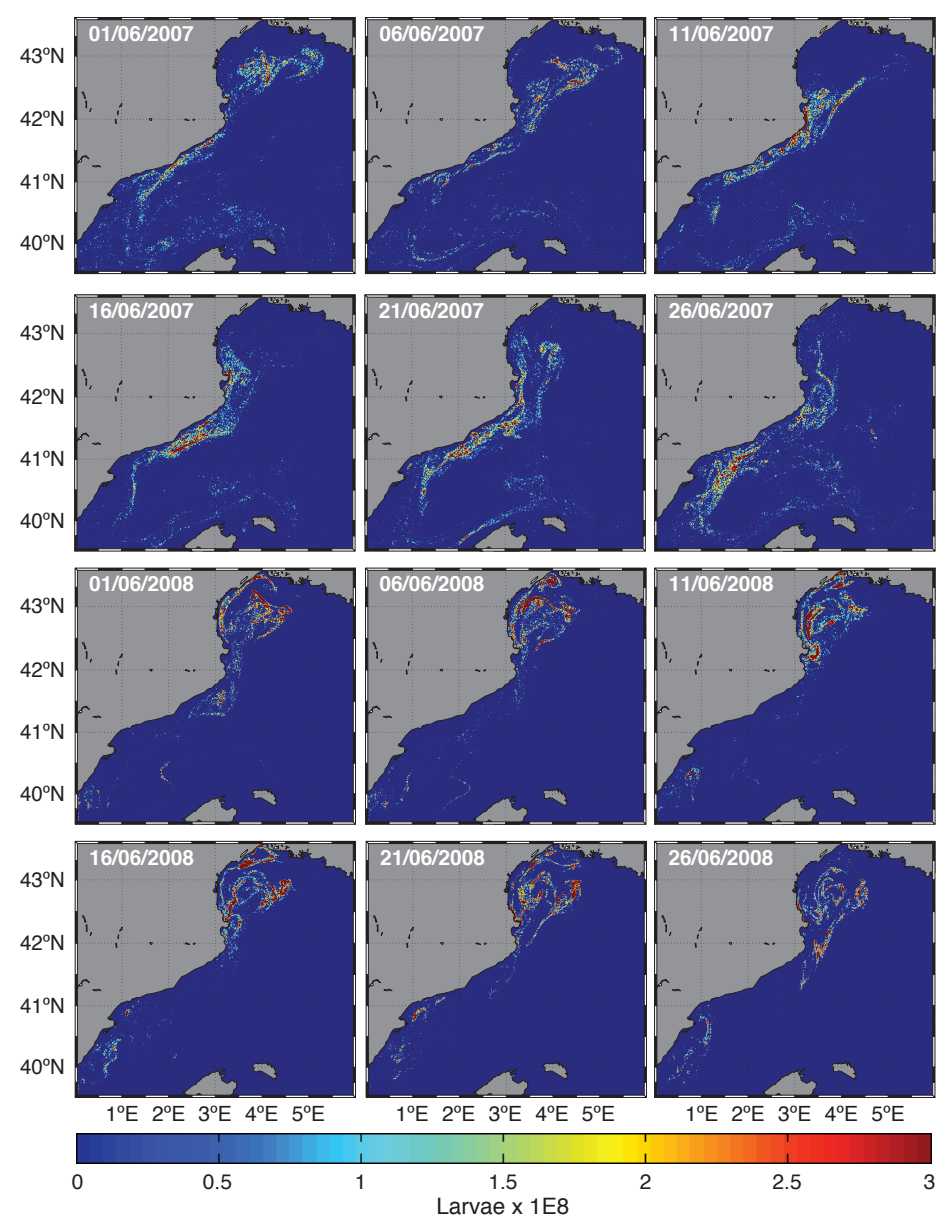

Figure 7: Simulated horizontal distributions of European anchovy larvae at $14 \mathrm{~mm}$ from the IBM. Each map corresponds to a different biological experiment. The release time is indicated in the left corner of each map. The color-scale represents larvae $\times 10^{8}$.

The TS is higher in 2008 than in 2007 and the release date that provides the highest TS is the $11^{\text {th }}$ of June 2008 (Table 6.5). 


\begin{tabular}{crrrrrrrr}
\hline $\begin{array}{c}\text { Release } \\
\text { date }\end{array}$ & $\begin{array}{r}\text { GoL } \\
\text { East }\end{array}$ & $\begin{array}{r}\text { GoL } \\
\text { West }\end{array}$ & Pala. & Barcel. & $\begin{array}{r}\text { Ebro } \\
\text { Delta }\end{array}$ & $\begin{array}{r}\text { Valen. } \\
\text { North }\end{array}$ & $\begin{array}{c}\text { Balearic } \\
\text { Islands }\end{array}$ & $\begin{array}{c}\text { Total. } \\
\text { TS }\end{array}$ \\
\hline $06 / 01 / 07$ & 5.23 & 11.47 & 5.93 & 9.95 & 3.87 & 1.72 & 1.01 & 39.18 \\
$06 / 06 / 07$ & 4.78 & 5.59 & 5.89 & 8.40 & 3.74 & 3.14 & 0.54 & 32.08 \\
$06 / 11 / 07$ & 0.01 & 2.82 & 24.91 & 12.28 & 5.33 & 1.87 & 0.73 & 47.94 \\
$06 / 16 / 07$ & 0.02 & 10.05 & 11.48 & 14.08 & 4.68 & 1.72 & 0.66 & 42.69 \\
$06 / 21 / 07$ & 0.34 & 9.05 & 13.74 & 12.11 & 7.33 & 0.84 & 0.40 & 43.81 \\
$06 / 26 / 07$ & 0.28 & 3.70 & 7.54 & 6.06 & 14.32 & 1.39 & 0.10 & 33.39 \\
$06 / 01 / 08$ & 21.25 & 30.54 & 6.91 & 0.90 & 0.68 & 5.15 & 0.00 & 65.43 \\
$06 / 06 / 08$ & 23.17 & 42.31 & 3.07 & 0.26 & 1.74 & 5.44 & 0.00 & 75.99 \\
$06 / 11 / 08$ & 20.85 & 44.95 & 7.09 & 0.05 & 4.76 & 2.69 & 0.00 & 80.39 \\
$06 / 16 / 08$ & 20.47 & 36.63 & 5.23 & 0.49 & 6.77 & 4.10 & 0.00 & 73.68 \\
$06 / 21 / 08$ & 12.92 & 37.31 & 4.52 & 1.83 & 8.67 & 3.63 & 0.00 & 68.88 \\
$06 / 26 / 08$ & 5.61 & 24.59 & 4.11 & 0.38 & 10.47 & 4.71 & 0.00 & 49.86 \\
\hline
\end{tabular}

Table 5: Transport success (TS) to each nursery area in the Individual-based model (IBM) and the total sum of the TS by release date. TS is the number of particles that were transported to a nursery area divided by the total of particles released, 9218 in each experiment in 2007 and 9220 in each experiment in 2008. 
The OTS represents between 25 and $45 \%$ of the TS in each experiment. The advection of particles to specific areas is an isolated phenomena that enhances the pre-recruitment, for example, Palamos and Barcelona received a high number of particles from GoL only on the $11^{\text {th }}$ of June 2007. Moreover, the transport of particles from continental to Balearic Islands waters is only observed in 2007 and the high accumulation of particles in GoL West transported from GoL East is only observed in 2008 (Figs. 6.5 and 6.7).

There are inter-annual differences in LTS, the LTS is higher in 2008 than in 2007. The retention of particles in the GoL in 2008 promote the LTS and, in consequence, in both years, the TS (Fig. 6.8).

\section{Discussion}

The NW Mediterranean is a very complex region from an hydrodynamical point of view. Several processes play important roles in the water circulation that influences the ichthyoplankton transport, such as the strong general circulation along the continental slope, the formation of dense water both on the shelf and offshore, seasonal variations in the stratification process and the extreme energies associated with meteorological conditions (André et al., 2005; Millot, 1990). The mesoscale oceanographic processes have been generally proposed as powerful explanatory variables for predicting the recruitment of marine populations that have pelagic early life stages. Concentration, retention and enrichment are considered the "triad" of oceanographic conditions influencing the life cycle of pelagic species (Bakun, 1996). However, the hydrodynamic conditions and the Lagrangian transport can not explain the totality of the processes involved in the advection transport and recruitment 


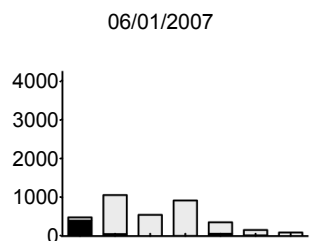

$06 / 06 / 2007$

$06 / 11 / 2007$

66/16/2007
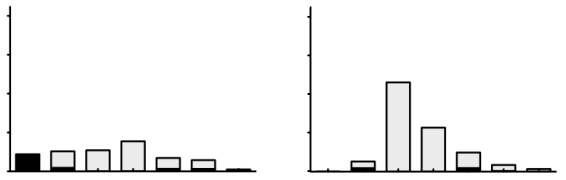

$06 / 21 / 2007$

$06 / 26 / 2007$
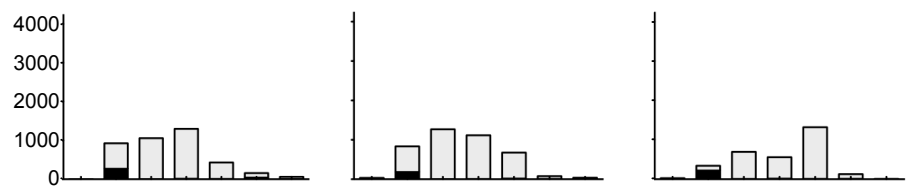

$06 / 01 / 2008$

$06 / 06 / 2008$

$06 / 11 / 2008$
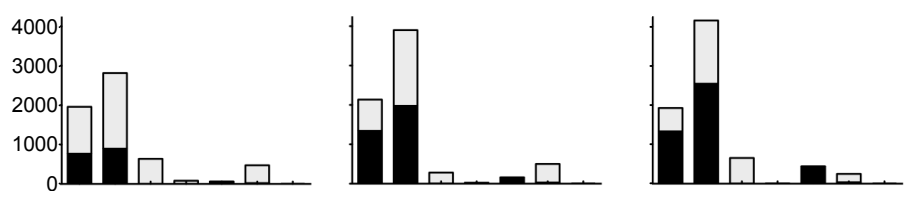

$06 / 16 / 2008$

$06 / 21 / 2008$

$06 / 26 / 2008$
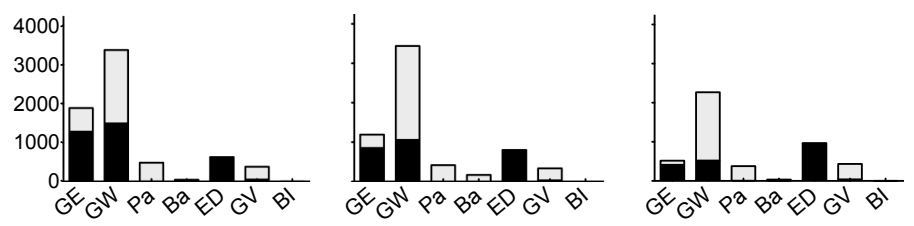

Figure 8: Outsider (gray bars) and local (black bars) larvae transported to each nursery area in the Individual-based model (IBM) for each release date. Outsider transport (OTS) is an indicator of the exportation of particles out to the spawning zone and local transport (LTS) is an indicator of retention of particles in the spawning zone. The y axis represents larvae $\times 10^{8}$. The areas in $\mathrm{x}$ axis are: GE-GoL East, GW-GoL West, Pa-Palamos, BaBarcelona, ED-Ebro Delta, GV-Gulf of Valencia and BI-Balearic Islands. Dates are in $\mathrm{mm} / \mathrm{dd} /$ yyyy format. 
of ichthyoplankton. For example, the temporal synchronicity in spawning, physiological condition and age of the spawners and the egg fertilization play an important role in the dispersion despite not being completely understood (Pineda et al., 2007). Moreover, as the mesoscale oceanographic processes that control recruitment may have different roles depending on the area, season and scale, among other factors, it is important to set the framework for the transport experiments.

According to Tudela et al. (2002), feeding behavior of anchovy larvae appears to be light-dependent and its occurs mainly during daytime. The feeding behavior of the larvae is visual - in other words, they select their food (Hunter, 1977) and its distribution is closely related to the productive layers (Palomera, 1991). The DVM sub-model does not adjust the vertical position of larvae exactly to the field data because anchovy larvae is an active feeder. In the ocean, the larvae can be found above and below the modeled depth. The position of larvae in the DVM sub-model is a compromise between the sunlight intensity, average migration extent and the active feeding behavior.

The experiments performed with an average climatology showed that the incorporation of a DVM scheme in the transport model IBM strongly influenced the larval transport (i.e. distances, trajectories travelled and final position). This suggests that under certain oceanographic conditions a DVM scheme optimizes retention while minimizing the export. In consequence, the hypothesis of anchovy using off-shore waters for recruitment cannot be excluded (Irigoien et al., 2007). The high productivity is generally associated with higher larval growth rate. Nevertheless Cotano et al. (2008) found that a high food concentration in coastal waters did not cause an increased an- 
chovy growth rate in Bay of Biscay. Lower mortality in areas with lower food availability might be a consequence of tradeoffs or developmental niche shifts, as certain size classes might take refuge in less profitable feeding habitats Cotano et al. (2008). Apparently, these results are contrary to the triad concept (Bakun, 1996), where the enrichment plays an important role and models predict minimum or no survival in the less productive oceanic area (Allain et al., 2007). However, the triad concept has been developed for upwelling areas and the retention probably requires a wider interpretation when the general circulation allows the larvae to return to the shelf. Our results showed that when we incorporate the DVM scheme the larval growth is lower. This can be due to larval exposure to the colder Rhone plume and sub-surface waters. The slower growth could represent strategies that minimize predation pressure, as smaller larvae are difficult to detect and would increase the probability of reaching the nursery areas (Cotano et al., 2008). In consequence, retention and enrichment should not be broadly used as indicators of higher recruitment.

The passive transport experiment had the particles less clustered compared to the biological experiment, where the particles were aggregated depending on the mesoscale oceanographic structures, evidencing a transport associated to filaments (La Violette et al., 1990) and meanders (Madec et al., 1991; Herbaut et al., 1996). Therefore, the inclusion of behavior mechanisms affects the general dispersion pattern, which subsequently conditions the recruitment success.

The transport and advection associated to filaments has been identified for European anchovy in the NW Mediterranean (Sabatés et al., 2004), 
Canary Islands (Bécognée et al., 2009), Benguela (Shannon et al., 1996) and Humboldt current (Parada et al., 2012) ecosystems among others. In the GoL, the complex continental slope is intersected by several irregular canyons. These irregularities generate mesoscale current features, such as meanders, filaments and secondary eddies on the inner side of the North Current (Flexas et al., 2002; La Violette et al., 1990; Tintoré et al., 1990; Wang et al., 1988). One plausible explanation for the aggregation of larvae in filaments is that DVM behavior reduces the number of particles escaping from the North Current, as deeper waters represent a barrier for escaping this current. In a previous study, focused on zooplankton transport in NW Mediterranean, simulations with DVM show less spreading of particles and a decrease in the number of them reaching the open boundary, particularly for the ones released at $5 \mathrm{~m}$ (Qiu et al., 2010). The inclusion of a DVM scheme in larvae transport simulations highlights the importance of coupling biological behavior, oceanographic mesoscale characteristics and stratification for the ecological interpretation of dispersion.

In order to evaluate the larval transport, a biophysical model should include larval behavior and physical mechanisms, considering their variability at multiple scales. Larvae should not be only considered as planktonic organisms drifting with the ocean currents and moving at a small-scale (millimeters to centimeters). As suggested by Pineda et al. (2007), larvae are complex and capable organisms that develop the ability to feed, avoid predation, and move within the pelagic environment. Thus, behavior plays a role in the equation of larval transport as important as advection and diffusion.

Our experiments show that there was larval retention near the spawning 
sites in 2008. However, regarding length28, differences between years were approximately $0.15 \mathrm{~mm}$; this difference, despite being significant, is small in physiological terms. We conclude that larval growth was not affected by the inter-annual variability of the retention phenomena. Nevertheless, we are not considering retention as a measure of the reproductive success. The larvae can reach a nursery area at both a high and at a low retention scenarios. We evaluated the individual reproduction success as a binary response, which we call pre-recruitment success. This response was positive when a $14 \mathrm{~mm}$ larvae was within one of the seven potential nursery areas.

The effects analyses of DVM on the horizontal transport based on the complete series from hydrodynamic model showed that distances and trajectories travelled by larvae to the nursery areas were strongly influenced by spawning area and date, i.e., a temporal factor determines the retention areas. Other mechanisms that could affect the transport include surface gravity waves (Monismith and Fong, 2004), barotropic tidal currents (Hare et al., 2002) cross-shore winds (Tapia et al., 2004), wind forcing inter-annual variation (Agostini and Bakun, 2002; Churchill et al., 2011) flow convergence and Ekman transport (Agostini and Bakun, 2002). These mechanisms should also have a positive or negative effect depending on the geographical, temporal and ecological context. For example the turbulence caused by strong winds both in the California Current and in the Bay of Biscay had negative effects on the anchovy larval feeding and survival (Bergeron, 2000; Lasker, 1978; Peterman and Bradford, 1987). However, in the Bay of Biscay a positive relationship between the frequency of upwelling events, due to north-easterly winds, and anchovy recruitment was found using a regional scale correlation 
analysis (Allain et al., 2001; Borja et al., 1998).

We confirm that temporal synchronicity in age, spawners, condition and egg fertilization determine the pre-recruitment success. Regarding the spawning areas, there was a temporal (spawning date) effect over the pre-recruitment success. Larvae from the spawning areas GoL East, GoL West, Ebro Delta and GoV had higher probability of reaching nursery areas, comparing to larvae from Palamos and Barcelona. We can not make predictions over larvae coming from the Balearic Islands, as this area has not been associated with anchovy spawning and the egg abundance is low. Therefore this area was not included as a spawning zone. The other factors included in the sensitivity analysis (temperature, salinity and floor depth at spawning), despite being significant, had a low predictability of the pre-recruitment success.

Larvae from spawning areas at a depth between approximately 5 and 90 $\mathrm{m}$ had higher pre-recruitment probability than larvae from deeper spawning areas. The depth where adults spawn $(5-15 \mathrm{~m})$ did not have significant effects over the pre-recruitment success, as the egg buoyancy and depth is adjusted through the development time until hatching (Ospina-Alvarez et al., 2012). In consequence, the release depth was excluded from the sensitivity analysis. Temperature and salinity at spawning sites were significant factors regarding the prediction of the pre-recruitment success. However their predictability was low and we highlight that, in general, larvae from spawning areas with low temperature and salinity $\left(14.0-18.5^{\circ} \mathrm{C}\right.$ and $\left.34.8-36.7\right)$ have higher probability of being recruited.

The objective of the GAM was to elucidate if a spline smooth of the initial independent variables could explain the pre-recruitment success at a 
greater extent. The independent variables were not included as ranges as we maintained the individual values of longitude, latitude, depth floor, temperature and salinity at spawning sites for each of the released particles. Overall, our GAM included 101,935 particles and, despite the model and all the selected independent variables were highly significant, we conclude that pre-recruitment success can not be predicted from the spawning conditions. The non-explained variance was higher than $80 \%$; using only initial conditions, neither the GAM nor the GLM, are effective predictive tools.

The coupling of the sensitivity analyses with geo-statistical and transport models are potential management tools with a high prediction power. We evaluated the importance of the seven proposed nursery areas using the position of larvae at $14 \mathrm{~mm}$ in the biological behavior experiments and quantifying TS, LTS and OTS. The highest mean TS was observed in 2008 (69.04\%), compared with $39.85 \%$ in 2007 and reaching in certain dates $80 \%$ (11 ${ }^{\text {th }}$ June 2008). The OTS was similar in both years $(35.84 \%$ in 2007 and $37.11 \%$ in 2008). The LTS was higher in 2008 (31.93\%) than in 2007 (4.01\%). When LTS was high so it was TS, which indicates a cause-effect relationship between retention and TS. In the years with hydrodynamic conditions promoting larval retention within the spawning areas the pre-recruitment rate was higher.

Taking into account all the discussed results, we conclude that the GoL is the most important area for European anchovy reproduction at the NW Mediterranean scale. The pre-recruitment in the GoL was higher in those years when the larvae retention is favored. However, at a regional scale the Ebro Delta is of great importance for the European anchovy reproduction, 
as, despite TS was low in this site compared with the GoL, it was relatively constant over the two sampling years. The hydrodynamic conditions enhance both OTS and LTS and this is an important characteristic for a reproduction area as it promotes genetic population connectivity.

The inter-annual variability in the retention of particles in GoL might be linked with mesoscale processes related with the formation of sub-meso and mesoscale eddies. These eddies are generated by the accumulation of potential energy in the southwestern GoL. This accumulation is a consequence of the Tramontane negative wind stress curl; a warm and less dense water body can be isolated and fed by a coastal current carrying warm water from the Catalan Sea. In summer, this structure can generate a strong anticyclonic eddy (Garreau et al., 2011). The eddies are suggested as physical mechanisms that can affect the ichthyoplankton transport (Sponaugle et al., 2002; Bassin et al., 2005; Lobel and Robinson, 1986; Logerwell and Smith, 2001). The "LATEX" eddies are related with extreme wind events, and in the NW Mediterranean these eddies act as a temporal barrier between GoL and Catalan Sea for the European anchovy, consequently accumulating higher number of particles in continental waters of GoL. A low number of extreme wind events related with the Tramontane and Mistral occur in the summer season, matching with the spawning peak of European anchovy.

After a long period of Tramontane, a burst of southeasterlies and northerlies appear to detach the LATEX eddy. This flows out of the GoL, migrating along the Catalan continental slope and continues into the Balearic Sea as the CATALAN eddy (Garreau et al., 2011). The channelled Tramontane induces a wind stress curl, generating an anticyclonic and a cyclonic struc- 
ture, the upwelled water isolates the anticyclonic eddy from the deep ocean surface layer and a warm coastal current feeds the anticyclonic structure (Garreau et al., 2011). Additionally, this occasional South-North current can act as a transport mechanism for carrying larvae from the Catalan coast to GoL. Our results showed that some larvae from the Catalan coast were pre-recruited in the west of the GoL, but their numbers were low compared to larvae recruited locally or transported from Eastern GoL. Connectivity defined as the exchange of individuals among geographically separated subpopulations (Cowen et al., 2000) exists between subpopulations from the Catalan coast and GoL following a South-North direction. This phenomena is not in accordance with other authors that suggest a physical barrier of exchange, associated with a thermal front, for the biological particles between these two areas (Sabatés et al., 2009). The connection between two areas was previously suggested by Garreau et al. (2011). When the hydrodynamic conditions were not favoring the formation of LATEX eddies, eggs and larvae were advected on the Catalan shelf toward the Balearic Sea and the Balearic Front, following the global circulation pattern. The connectivity between GoL and Catalan coast is therefore a two-way phenomena, as a large fraction of the larvae from the spawning areas in the GoL are prerecruited in the Catalan Coast, and specially in Ebro Delta where they are accumulated by the Balearic Front. This front is not an impassable barrier as the simulations showed that some larvae trespass it and recruit in the Balearic Islands. We conclude that there is interconnectivity between all the European anchovy sub-populations in the NW Mediterranean, but a further genetic studies should be developed to confirm this. 
In any of the discussed conditions the larvae were transported forming filaments that generally avoided the nucleus of the eddies and the central part of the NC. This generated a transport belt in the area between two eddies, between an eddy and the $\mathrm{NC}$ and between a density current and $\mathrm{NC}$. This phenomena, that could be important for the advection towards oceanic waters, is minimized in the NW Mediterranean by the barrier effect that exerts strong currents like the NC. The transport of ichthyoplankton within transport belts had been previously observed in other areas (Epifanio and Garvine, 2001; García et al., 2002; Morello and Arneri, 2009; Park et al., 2007) and the transport forming filaments as a consequence of the formation of eddies or upwellings had been identified in several transport simulation experiments (Bécognée et al., 2006, 2009; Nicolle et al., 2009; Rodríguez et al., 1999, 2006).

The formation of schools was facilitated by the transport in filaments. The schooling behavior is an indispensable anti-predatory behavior (Olst and Hunter, 1970; Partridge, 1981; Zheng et al., 2005) that starts at the larvae with a series of morphological and physiological changes that promote their aggregation (Tsukamoto and Tsukamoto, 1999). Schooling behavior with a parallel orientation and inter-individual distance of one-body length might be well established in the anchovy at early post-flexion stages (Somarakis and Nikolioudakis, 2010). These morphological and behavioral changes, including strong phototaxis, development of sensory or swimming organs, fin formation and inflection of allometric growth occur at approximately $12 \mathrm{~mm}$ length in anchovy (Hunter, 1977; Somarakis and Nikolioudakis, 2010) and probably setting the conditions for the recruitment in coastal waters. 
We emphasize the lack of knowledge about the European anchovy nursery areas in the NW Mediterranean. Data on the abundance and the preferred areas for larvae at hatching time is not available. Such information is still relatively scarce and patchy in comparison with data on egg abundance or preferred areas for juveniles and adults. Our interpretation of the results is the best compromise between natural history and fishermen knowledge.

We conclude that up to date the biological behavior experiments developed are the most realistic ones for the NW Mediterranean. We used as the release position at spawning the egg abundance recorded from surveys designed specially for this porpoise. Additionally, we used a validated hydrodynamic model coupled with an IBM improved with realistic behavior models: (1) egg buoyancy changing through development and (2) a DVM scheme structured by age and size. Our results clearly showed that anchovy larvae migrating between different depths are subjected to different currents and thus their Lagrangian trajectories change. We underline that bottlenecks in larval transport modelling are related to the scarcity of knowledge in developmental biology and behavior of anchovy larvae and emergent mechanistic processes.

We encourage the scientific community in the NW Mediterranean for improving the model, by including a long-time series transport simulation experiment (e.g., the last decade), induced behavior (e.g., foraging, predator avoidance, schooling, directional horizontal swimming in response to environmental cues) and emerging properties (i.e., mortality), as an essential prerequisite for devising effective fishery management strategies. 


\section{Acknowledgements}

This research was conducted within the European project SARDONE (FP6-44294). Egg samples were obtained from the MPOCAT-DEPM surveys financed by Generalitat de Catalunya. A. Ospina-Alvarez benefited from a PhD grant of the JAE program (CSIC). We are grateful to P. Garreau and A. Nicolle for their support with MARS-3D hydrodynamic model outputs, as well as to P. Verley for his assistance in ICHTHYOP code and Miguel Bernal and Silvia de Juan for valuable exchange of information and ideas. Finally, the authors gratefully acknowledge the assistance of the captain and crew of the RV Garcia del Cid for their help during the cruise.

\section{References}

Agostini V, Bakun A. 'Ocean triads' in the Mediterranean Sea: physical mechanisms potentially structuring reproductive habitat suitability (with example application to European anchovy, Engraulis encrasicolus). Fish Oceanogr 2002;11(3):129-142.

Ahlstrom EH. Vertical distribution of pelagic fish eggs and larvae off California and Baja California. Fish Bull 1959;60:107-149.

Allain G, Petitgas P, Lazure P. The influence of mesoscale ocean processes on anchovy (Engraulis encrasicolus) recruitment in the Bay of Biscay estimated with a threedimensional hydrodynamic mode. Fish Oceanogr 2001; $10(2): 151-163$.

Allain G, Petitgas P, Lazure P. The influence of environment and spawning distribution on the survival of anchovy (Engraulis encrasicolus) larvae in 
the Bay of Biscay (NE Atlantic) investigated by biophysical simulations. Fish Oceanogr 2007;16(6):506-514.

André G, Garreau P, Garnier V, Fraunie P. Modelled variability of the sea surface circulation in the North-western Mediterranean Sea and in the Gulf of Lions. Ocean Dynam 2005;55:294-308.

Aoki I, Murayama T. Spawning pattern of the Japanese sardine Sardinops melanostictus off southern Kyushu and Shikoku, southwestern Japan. Mar Ecol Prog Ser 1993;97:127-134.

Bakun A. Patterns in the ocean: Ocean processes and marine population dynamics. San Diego: University of California Sea Grant, in cooperation with Centro de Investigaciones Biológicas de Noroeste, La Paz, Baja California Sur, Mexico, 1996.

Bassin C, Washburn L, Brzezinski M, McPhee-Shaw E. Sub-mesoscale coastal eddies observed by high frequency radar: A new mechanism for delivering nutrients to kelp forests in the Southern California Bight. Geophys Res Lett 2005;32(12):604-608.

Bécognée P, Almeida C, Barrera A, Hernández-Guerra A, Hernández-León S. Annual cycle of clupeiform larvae around Gran Canaria Island, Canary Islands. Fish Oceanogr 2006;15(4):293-300.

Bécognée P, Moyano M, Almeida C, Rodríguez J, Fraile-Nuez E, HernándezGuerra A, et al. Mesoscale distribution of clupeoid larvae in an upwelling filament trapped by a quasi-permanent cyclonic eddy off Northwest Africa. Deep-Sea Res (1 Oceanogr Res Pap) 2009;56(3):330-343. 
Begon M, Townsend C, Harper J. Ecology: from individuals to ecosystems. 4 ed. Oxford: Blackwell, 2006.

Bergeron JP. Effects of strong winds on the nutritional condition of anchovy (Engraulis encrasicolus) larvae in the Bay of Biscay, NE Atlantic, as inferred from an early field application of the DNA/C index. ICES J Mar Sci 2000;57:249-255.

Borja A, Uriarte A, Egana J, Motos L, Valencia V. Relationships between anchovy (Engraulis encrasicolus) recruitment and environment in the Bay of Biscay (1967-1996). Fish Oceanogr 1998;7(3-4):375-380.

Brickman D, Smith, PC. Lagrangian stochastic modeling in coastal oceanography. J Atmos Oceanic Technol 2002;19(1):83-99.

Brochier T, Colas F, Lett C, Echevin V, Cubillos L, Tam J, et al. Small pelagic fish reproductive strategies in upwelling systems: A natal homing evolutionary model to study environmental constraints. Prog Oceanogr 2009;83(1-4):261-269.

Brochier T, Lett C, Tam J, Freón P, Colas F, Ayón P. An individual-based model study of anchovy early life history in the northern Humboldt Current system. Prog Oceanogr 2008;79:313-325.

Chavez F, Ryan J, Lluch-Cota SE, Niquen C M. From anchovies to sardines and back: multidecadal change in the Pacific Ocean. Science 2003; 299(5604):217-221.

Churchill JH, Runge J, Changsheng C. Processes controlling retention of springspawned Atlantic cod (Gadus morhua) in the western Gulf of Maine 
and their relationship to an index of recruitment success. Fish Oceanogr 2011;20(1):32-46.

Clark PJ, Evans FC. Distance to nearest neighbor as a measure of spatial relationships in populations. Ecology 1954;35(4):445-453.

Clobert J, Danchin E, Dhondt A, Nichols J. Dispersal. Oxford University Press, USA, 2001.

Cotano U, Irigoien X, Etxebeste E, Alvarez P, Zarauz L, Mader J, et al. Distribution, growth and survival of anchovy larvae (Engraulis encrasicolus L.) in relation to hydrodynamic and trophic environment in the Bay of Biscay. J Plankton Res 2008;30(4):467-481.

Cowen RK. Oceanographic influences on larval dispersal and retention and their consequences for population connectivity. In Sale PF, editor, Coral reef fishes: dynamics and diversity in a complex ecosystem, pp. 149-170. San Diego: Academic Press, 2006;

Cowen RK, Lwiza KMM, Sponaugle S, Paris CB, Olson DB. Connectivity of marine populations: open or closed? Science 2000;287:857-859.

Cruzado A, Velásquez Z, Pérez MdC, Bahamon N, Grimaldo NS, Ridolfi F. Nutrient fluxes from the Ebro River and subsequent across-shelf dispersion. Cont Shelf Res 2002;22(2):349-360.

Echevin V, Crepon M, Mortier L. Interaction of a coastal current with a gulf: application to the shelf circulation of the Gulf of Lions in the Mediterranean sea. J Phys Oceanogr 2003;33:188-206. 
Enright J, Hamner W. Vertical diurnal migration and endogenous rhythmicity. Science 1967;157(3791):937-941.

Epifanio CE, Garvine RW. Larval transport on the Atlantic continental shelf of North America: a review. Estuar Coast Shelf S 2001;52(1):51-77.

Flexas M, Durrieu De Madron X, Garcia M, Canals M, Arnau P. Flow variability in the Gulf of Lions during the MATER HFF experiment (MarchMay 1997). J Marine Syst 2002;33-34:197-214.

Fortier L, Leggett WC. Vertical migrations and transport of larval fish in a partially mixed estuary. Can J Fish aquat Sci 1983;67:1755-1767.

Galarza JA, Carreras-Carbonell J, Macpherson E, Pascual M, Roques S, Turner GF, et al. The influence of oceanographic fronts and early-lifehistory traits on connectivity among littoral fish species. PNAS 2009; 106(5):1473-1478.

Garcia A, Cortes D, Ramirez T. Daily larval growth and RNA and DNA content of the NW Mediterranean anchovy Engraulis encrasicolus and their relations to the environment. Mar Ecol Prog Ser 1998;166:237-245.

García C, Prieto L, Vargas M, Echevarría F, García Lafuente J, Ruiz J, et al. Hydrodynamics and the spatial distribution of plankton and TEP in the Gulf of Cádiz (SW Iberian Peninsula). J Plankton Res 2002;24(8):817-833.

Garreau P, Garnier V, Schaeffer A. Eddy resolving modelling of the Gulf of Lions and Catalan Sea. Ocean Dynam 2011;61(7):991-1003. 
Gauthier S, Rose G. Acoustic observation of diel vertical migration and shoaling behaviour in Atlantic redfishes. J Fish Biol 2002;61(5):1135-1153.

Goarant A, Petitgas P, Bourriau P. Anchovy (Engraulis encrasicolus) egg density measurements in the Bay of Biscay: evidence for the spatial variation in egg density with sea surface salinity. Mar Biol 2007;151:1907-1915.

Grant WS, Lecomte F, Bowen BW. Biogeographical contingency and the evolution of tropical anchovies (genus Cetengraulis) from temperate anchovies (genus Engraulis). J Biogeogr 2010;37:1352-1362.

Haldorson L, Prichett M, Paul AJ, Ziemann D. Vertical distribution and migration of fish larvae in a Northeast Pacific bay. Mar Ecol Prog Ser 1993;101:67-80.

Haney J. Diel patterns of zooplankton behavior. Bull Mar Sci 1988;43(3):583603.

Hare JA, Churchill JH, Cowen RK, Berger TJ, Cornillon PC, Dragos P, et al. Routes and rates of larval fish transport from the southeast to the northeast United States continental shelf. Limnol Oceanogr 2002;47(6):1774-1789.

Hastie T, Tibshirani RJ. Generalized Additive Models. 1 ed. London: Chapman and Hall, 1990.

Haug T, Kjorsvik E, Solemdal P. Influence of some physical and biological factors on the density and vertical distribution of Atlantic halibut Hippoglossus hippoglossus eggs. Mar Ecol Prog Ser 1986;33:207-216. 
Hays G. A review of the adaptive significance and ecosystem consequences of zooplankton diel vertical migrations. Hydrobiologia 2003;503(1):163-170.

Herbaut C, Mortier L, Crepon M. A sensitivity study of the general circulation of the Wertern Mediterranean Sea. I: The response to density forcing through the straits. J Phys Oceanogr 1996;26(1):65-84.

Hinckley S, Hermann A, Megrey BA. Development of a spatially explicit, individual-based model of marine fish early life history. Mar Ecol Prog Ser 1996;139:47-68.

Hunter J. Behavior and survival of northern anchovy Engraulis mordax larvae. Calif Coop Oceanic Fish Invest Rep 1977;pp. 138-146.

Huret M, Petitgas P, Woillez M. Dispersal kernels and their drivers captured with a hydrodynamic model and spatial indices: a case study on anchovy (Engraulis encrasicolus) early life stages in the Bay of Biscay. Prog Oceanogr 2010;87:6-17.

Irigoien X, Fiksen Ø, Cotano U, Uriarte A, Alvarez P, Arrizabalaga H, et al. Could Biscay Bay Anchovy recruit through a spatial loophole? Prog Oceanogr 2007;74(2-3):132-148.

La Violette P, Tintoré J, Font J. The surface circulation of the Balearic Sea. J Geophys Res 1990;95(2):1559-1568.

Lasker R. The relation between oceanographic conditions and larval anchovy food in the California current : identification of factors contributing to recruitment failure. Tech. rep., 1978. 
Lazure P, Dumas F. An external-internal mode coupling for a 3D hydrodynamical model for applications at regional scale (MARS). Adv Water Resour 2008;31:233-250.

Lecomte F, Grant WS, Dodson JJ, Rodriguez-Sanchez R, Bowen BW. Living with uncertainty: genetic imprints of climate shifts in East Pacific anchovy (Engraulis mordax) and sardine (Sardinops sagax). Mol Ecol 2004; 13(8):2169-2182.

Lett C, Penven P, Ayón P, Freón P. Enrichment, concentration and retention processes in relation to anchovy (Engraulis ringens) eggs and larvae distributions in the northern Humboldt upwelling ecosystem. J Marine Syst 2007;64(1-4):189-200.

Lett C, Verley P, Mullon C, Parada CE, Brochier T, Penven P, et al. A Lagrangian tool for modelling ichthyoplankton dynamics. Envir Model Softw 2008;23:1210-1214.

Lloret J, Palomera I, Salat J, Sole I. Impact of freshwater input and wind on landings of anchovy (Engraulis encrasicolus) and sardine (Sardina pilchardus) in shelf waters surrounding the Ebre (Ebro) River delta (north-western Mediterranean). Fish Oceanogr 2004;13(2):102-110.

Lo N. A model for temperature-dependent northern anchovy egg development and an automated procedure for the assignment of age to staged eggs. In Lasker R, editor, An egg production method for estimating spawning biomass of pelagic fish: application to the Northern anchovy, Engraulis 
mordax, pp. 43-50. Wash. DC: U.S. Department of Commerce, NOAA Technical Report NMFS-36, 1985;

Lobel PS, Robinson AR. Transport and entrapment of fish larvae by ocean mesoscale eddies and currents in Hawaiian waters. Deep-Sea Res (A Oceanogr Res Pap) 1986;33(4):483-500.

Logerwell E, Smith P. Mesoscale eddies and survival of late stage Pacific sardine (Sardinops sagax) larvae. Fish Oceanogr 2001;10(1):13-25.

Madec G, Chartier M, Delecluse P, Crepon M. A three-dimensional numerical study of deep-water formation in the northwestern Mediterranean Sea. J Phys Oceanogr 1991;21(9):1349-1371.

Mantel N. The detection of disease clustering and a generalized regression approach. Cancer Res 1967;27(1):209-220.

Matsuura Y, Kitahara E. Horizontal and vertical distribution of anchovy Engraulis anchoita eggs and larvae off Cape Santa Marta Grande in southern Brazil. Arch Fish Mar Res 1995;42(3):239-250.

Millot C. The Gulf of Lions' hydrodynamics. Cont Shelf Res 1990;10(911):885-894.

Monismith SG, Fong DA. A note on the potential transport of scalars and organisms by surface waves. Limnol Oceanogr 2004;49:1214-1217.

Morello EB, Arneri E. Anchovy and sardine in the Adriatic sea - an ecological review. In Gibson R, Atkinson R, Gordon J, editors, Oceanography 
and marine biology: An annual review, pp. 209-256. Boca Raton, USA: Taylor \& Francis, 2009;

Moser HG, Ahlstrom EH. Staging anchovy eggs. In Lasker R, editor, An egg production method for estimating spawning biomass of pelagic fish: application to the Northern anchovy, Engraulis mordax, pp. 43-50. Wash. DC: U.S. Department of Commerce, NOAA Technical Report NMFS-36, $1985 ;$

Mullon C, Cury PM, Penven P. Evolutionary individual-based model for the recruitment of anchovy (Engraulis capensis) in the southern Benguela. Can J Fish aquat Sci 2002;59(5):910-922.

Mullon C, Freón P, Parada CE, van der Lingen C, Huggett J. From particles to individuals: modelling the early stages of anchovy (Engraulis capensis/encrasicolus) in the southern Benguela. Fish Oceanogr 2003;12(45):396-406.

Nicolle A, Garreau P, Liorzou B. Modelling for anchovy recruitment studies in the Gulf of Lions (Western Mediterranean Sea). Ocean Dynam 2009; 59:953-968.

Olivar M, Salat J, Palomera I. Comparative study of spatial distribution patterns of the early stages of anchovy and pilchard in the NW Mediterranean Sea. Mar Ecol Prog Ser 2001;217:111-120.

Olst JCv, Hunter J. Some aspects of the organization of fish schools. Can J Fish Aquat Sci 1970;27(7):1225-1238. 
Ospina-Alvarez A, Palomera I, Parada CE. Changes in egg buoyancy during development and its effects on the vertical distribution of anchovy eggs. Fish Res 2012;117-118:86-95.

Page FH, Frank KT, Thompson KR. Stage dependent vertical distribution of haddock (Melanogrammus aeglefinus) eggs in a stratified water column: observations and model. Can J Fish aquat Sci 1989;46(S1):55-67.

Palomera I. Vertical distribution of eggs and larvae of Engraulis encrasicolus in stratified waters of the western Mediterranean. Mar Biol 1991;111:3744 .

Palomera I, Morales-Nin B, Lleonart J. Larval growth of anchovy, Engraulis encrasicolus, in the Western Mediterranean Sea. Mar Biol 1988;99:283-291.

Palomera I, Olivar M, Salat J, Sabatés A, Coll M, Garcia A, et al. Small pelagic fish in the NW Mediterranean sea: An ecological review. Prog Oceanogr 2007;74(2-3):377-396.

Parada CE, Colas F, Soto-Mendoza S, Castro L. Effects of seasonal variability in across- and alongshore transport of anchoveta (Engraulis ringens) larvae on model-based pre-recruitment indices off central Chile. Prog Oceanogr 2012;92-95(0):192-205.

Parada CE, Mullon C, Roy C, Freón P, Hutchings L, van der Lingen C. Does vertical migratory behaviour retain fish larvae onshore in upwelling ecosystems? A modelling study of anchovy in the southern Benguela. African J of Marine Sc 2008;30(3):437-452. 
Parada CE, van der Lingen C, Mullon C, Penven P. Modelling the effect of buoyancy on the transport of anchovy (Engraulis capensis) eggs from spawning to nursery grounds in the southern Benguela: an IBM approach. Fish Oceanogr 2003;12(3):170-184.

Park W, Douglas DC, Shirley TC. North to Alaska: evidence for conveyor belt transport of Dungeness crab larvae along the West coast of the United States and Canada. Limnol Oceanogr 2007;52(1):248-256.

Partridge B. Internal dynamics and the interrelations of fish in schools. J Comp Physiol A Neuroethol Sens Neural Behav Physiol 1981;144(3):313325.

Peterman R, Bradford M. Wind speed index and mortality rate of a marine fish, the northern anchovy (Engraulis mordax). Science 1987;235:354-356.

Pineda J, Hare JA, Sponaugle S. Larval transport and dispersal in the coastal ocean and consequences for population connectivity. Oceanography 2007; 20(3):22-39.

Qiu Z, Doglioli A, Hu Z, Marsaleix P, Carlotti F. The influence of hydrodynamic processes on zooplankton transport and distributions in the North Western Mediterranean: estimates from a Lagrangian model. Ecol Model 2010;221:2816-2827.

R Development Core Team. R: A Language and environment for statistical computing. Vienna, Austria, 2.12.2 ed., 2010.

Riveiro I, Guisande C, Iglesias P, Basilone G, Cuttitta A, Giráldez A, et al. 
Identification of subpopulations in pelagic marine fish species using amino acid composition. Hydrobiologia 2011;670:189-199.

Rodríguez J, Hernández-León S, Barton E. Mesoscale distribution of fish larvae in relation to an upwelling filament of Northwest Africa. Deep-Sea Res (1 Oceanogr Res Pap) 1999;46:1969-1984.

Rodríguez J, Hernández-León S, Barton E. Vertical distribution of fish larvae in the Canaries-African coastal transition zone in summer. Mar Biol 2006; 149(4):885-897.

Sabatés A, Salat J, Masó M. Spatial heterogeneity of fish larvae across a meandering current in the Northwestern Mediterranean. Deep-Sea Res (1 Oceanogr Res Pap) 2004;51(4):545-557.

Sabatés A, Salat J, Palomera I, Emelianov M, Fernández de Puelles M, Olivar M. Advection of anchovy (Engraulis encrasicolus) larvae along the Catalan continental slope (NW Mediterranean). Fish Oceanogr 2007;16(2):130141.

Sabatés A, Salat J, Raya V, Emelianov M, Segura-Noguera M. Spawning environmental conditions of Sardinella aurita at the northern limit of its distribution range, the Western Mediterranean. Mar Ecol Prog Ser 2009; $385: 227-236$.

Salat J. Review of hydrographic environmental factors that may influence anchovy habitats in North Western Mediterranean. Sci Mar 1996;60(2):2132. 
Shannon LJ, Nelson G, Crawford RJM, Boyd AJ. Possible impacts of environmental change on pelagic fish recruitment: modelling anchovy transport by advective processes in the southern Benguela. Glob Chang Biol 1996; $2(5): 407-420$.

Silverman BW. Some Aspects of the Spline Smoothing Approach to NonParametric Regression Curve Fitting. J Roy Stat Soc B Met 1985;47(1):152.

Solemdal P, Sundby S. Vertical distribution of pelagic fish eggs in relation to species, spawning behaviour and wind conditions. ICES CM 1981;pp. $1-27$.

Somarakis S, Nikolioudakis N. What makes a late anchovy larva? The development of the caudal fin seen as a milestone in fish ontogeny. J Plankton Res 2010;32(3):317-326.

Somarakis S, Palomera I, Garcia A, Quintanilla L, Koutsikopoulos C, Uriarte A, et al. Daily egg production of anchovy in European waters. ICES J Mar Sci 2004;61:944-958.

Sponaugle S, Cowen RK, Shanks A, Morgan SG, Leis JM, Pineda J, et al. Predicting self-recruitment in marine populations: Biophysical correlates and mechanisms. Bull Mar Sci 2002;70(1):341-375.

Stenevik EK, Sundby S, Cloete R. Diel vertical migration of anchovy Engraulis encrasicolus larvae in the northern Benguela. African J of Marine Sc 2007;29(1):127-136. 
Tapia FJ, Pineda J, Ocampo-Torres FJ, Fuchs HL, Parnell PE, Montero P, et al. High-frequency observations of wind-forced onshore transport at a coastal site in Baja California. Cont Shelf Res 2004;24:1573-1585.

The MathWorks Inc. MATLAB@ 7. Natick, MA, 7.12.0.635 ed., 2011.

Tintoré J, Wang D, LaViolette P. Eddies and thermohaline intrusions of the shelf/slope front off the northeast Spanish coast. J Geophys Res 1990; 95:1627-1633.

Tsukamoto R, Tsukamoto K. School formation and concurrent developmental changes in carangid fish with reference to dietary conditions. Environ Biol Fish 1999;56:243-252.

Tudela S, Palomera I, Qu lez G. Feeding of anchovy Engraulis encrasicolus larvae in the north-west Mediterranean. J Mar Biol Ass 2002;82(2):349350 .

Urtizberea A, Fiksen $\varnothing$, Folkvord A, Irigoien X. Modelling growth of larval anchovies including diel feeding patterns, temperature and body size. J Plankton Res 2008;30(12):1369-1383.

Wang D, Vieira M, Salat J, Tintoré J, La Violette P. A shelf/slope frontal filament off the northeast Spanish coast. J Mar Res 1988;46(2):321-332.

Whitehead P, Nelson G, Wongratana T. FAO species catalogue. vol 7. clupeoid fishes of the world (Engraulidae). An annotated and ilustrated catalogue of the herrings, sardines, pilchards, sprats, shads anchovies and wolf-herrings. FAO Fish Synop 125 1988;7(2):305-579. 
Zender C, Jenks S, Wang D, Butowsky H, Capps S. NetCDF Operator (NCO Tools) 2011;p. GNU General Public License version 3.0 (GPLv3).

Zender CS. Analysis of self-describing gridded geoscience data with netCDF Operators (NCO). Envir Model Softw 2008;23(10-11):1338-1342.

Zheng M, Kashimori Y, Hoshino O, Fujita K, Kambara T. Behavior pattern (innate action) of individuals in fish schools generating efficient collective evasion from predation. J Theor Biol 2005;235(2):153-167. 